\title{
Rice Husk Ash as a Renewable Source for the Production of Value Added Silica Gel and its Application: An Overview
}

\author{
Ram Prasad *, and Monika Pandey
}

Department of Chemical Engineering \& Technology, Banaras Hindu University, Varanasi 221005, India

Received: 23th November 2011, Revised: 09th January 2012, Accepted: 10th January 2012

\begin{abstract}
In recent years, silica gels have developed a lot of interest due to their extraordinary properties and their existing and potential applications in science and technology. Silica gel has a wide range of applications such as a desiccant, as a preservation tool to control humidity, as an adsorbent, as a catalyst and as a catalyst support. Silica gel is a rigid three-dimensional network of colloidal silica, and is classified as: aqua-gel, alco-gel, xero-gel and aero-gel. Out of all known solid porous materials, aero-gels are particularly known for their high specific surface area, high porosity, low bulk density, high thermal insulation value, ultra low dielectric constant and low index of refraction. Because of these extraordinary properties silica aero-gel has many commercial applications such as thermal window insulation, acoustic barriers, super-capacitors and catalytic supports. However, monolithic silica aero-gel has been used extensively in high energy physics in Cherenkov radiation detectors and in shock wave studies at high pressures, inertial confinement fusion (ICF) radio-luminescent and micrometeorites. Silica gel can be prepared by using various sol gel precursors but the rice husk $(\mathrm{RH})$ is considered as the cheapest source for silica gel production. Rice husk is a waste product abundantly available in rice producing countries during milling of rice. This review article aims at summarizing the developments carried out so far in synthesis, properties, characterization and method of determination of silica, silica gel, silica aero-gel and silica xero-gel. The effect of synthesis parameters such as $\mathrm{pH}$, temperature of burning the rice husk, acid leaching prior to formation of rice husk ash (RHA) on the properties of final product are also described. The attention is also paid on the application of RH, RHA, silica, silica aero-gel and silica xero-gel. Development of economically viable processes for getting rice husk silica with specific properties assumes importance at this juncture. Copyright C 2012 by BCREC UNDIP. All rights reserved.
\end{abstract}

Keywords: Rice husk, Rice husk ash, Sodium silicate, Silica gel, Review

How to Cite: R. Prasad, and M. Pandey. (2012). Rice Husk Ash as a Renewable Source for the Production of Value Added Silica Gel and its Application: An Overview. Bulletin of Chemical Reaction Engineering \& Catalysis, 7 (1): 1-25

Permalink: http://ejournal.undip.ac.id/index.php/bcrec/article/view/1216

\section{Contents}

1. Introduction

1.1 Component and Structure of rice husk

1.2 Uses of rice husk

1.3 Uses of rice husk ash

1.4 Silica from rice husk

2. Effect of temperature on burning of rice husk
2.1 Amorphous and crystalline silica

2.2 Combustion of rice husk after leaching with acid

3. Silica gel

3.1 Classification of silica gel

3.2 Preparation of silica gel

3.3 Application of silica gel

* Corresponding Author, E-mail: rprasad.che@itbhu.ac.in (R. Prasad)

Tel.: +91542 2367323, fax: +915422368092. 
4. Silica xero-gel

4.1 Impurities present

4.2 Acid washing

4.3 Production of silica xero-gel

4.4 Effect of $\mathrm{pH}$ on production of silica xero-gel

4.5 Silica yield at various $\mathrm{pH}$

5. Silica aero-gel

5.1 Properties of silica aero-gel and method of determination

\section{Introduction}

Rice husk ( $\mathrm{RH})$ is one of the by-products obtained during milling of rice. This surrounds the paddy grain. It is reported that approximately 0.23 tons of rice husk (rice hull) is formed from every ton of rice produced [1]. World rice production is approximately 645 million tons. Asian farmers produce rice about $90 \%$ of total production of 100,000 tons or more, with two countries, China and India, growing more than half of the total crop [2]. In certain countries, it is sometimes used as a fuel for parboiling paddy in the rice mills and to power steam engines. The partially burnt rice husk in turn contributes to environmental pollution. It would be beneficial to the environment to recycle the waste to produce eco-material having high end value [3]. End use of any material including wastes depends on its structure, properties and mainly on chemical composition. Chemical compositions of rice husk vary from sample to sample. This variation is due to differences in climatic and geographical conditions, type of paddy etc [4-6]. The chemical analysis of rice husk is shown in Table $1 . \mathrm{SiO}_{2}$ is found to be $22.12 \%$, the organic material and water content is $74 \%$ and $\left(\mathrm{A}_{2} \mathrm{O}_{3}+\mathrm{Fe}_{2} \mathrm{O}_{3}+\mathrm{CaO}+\right.$ $\mathrm{MgO}$ ) constitute about $4 \%$. The percentage of $\mathrm{SiO}_{2}$ varies from 15 to $22 \%$.

Sharma et al., [5] analyzed all the reported data on organic constituents of rice husk after excluding silica and gave an average composition as given in the Table 2. The organic part is

Table 1. Chemical analysis of raw rice husk [5]

\begin{tabular}{cc}
\hline Constituent & Content (wt \%) \\
\hline Organic material and & 73.87 \\
moisture & \\
$\mathrm{Al}_{2} \mathrm{O}_{3}$ & 1.23 \\
$\mathrm{Fe}_{2} \mathrm{O}_{3}$ & 1.28 \\
$\mathrm{CaO}$ & 1.24 \\
$\mathrm{MgO}$ & 0.21 \\
$\mathrm{SiO}_{2}$ & 22.12 \\
$\mathrm{MnO}_{2}$ & 0.074 \\
\hline
\end{tabular}

5.2 Application of silica aero-gel

5.3 Synthesis of silica aero-gel

6. Comparison of characteristics of silica aero-gel and silica xero-gel

7. Conclusion

References

composed of cellulose, lignin and hemicellulose; the latter is a mixture of $\mathrm{D}$-xylose, L-arabinose, methylglucoronic acid and D-galactose.

\subsection{Components and Structure of Rice Husk}

It is generally reported that in rice husk, silica is predominantly in inorganic linkages, but some of the silica is also bonded covalently to the organic compounds. This portion of the silica is un -dissolved in alkali and can withstand very high temperatures [7]. It has been cleared that once the organic part of $\mathrm{RH}$ is extracted, the inorganic residue may be relatively pure, forming a better source for silica. Characterizations by Scanning electron microscopy (SEM), energy-dispersive Xray analysis (EDX) etc., suggest that silica is present all over, but is concentrated on protuberances and hairs (trichomes) on the outer epidermis, adjacent to the rice kernel $[5,8,9]$.

There is a significant variation in silica percentage. The silica is in hydrated amorphous form, either opal or silica gel. Figure 1 shows the SEM photographs of $\mathrm{RH}$ and Figure 2 clearly shows the protuberances and silica [10].

\subsection{Uses of Rice Husk}

A number of rice-producing countries including India are currently conducting research on industrial uses of rice husk. Some of the current

Table 2. Organic constituents of $\mathrm{RH}$ excluding silica [5]

\begin{tabular}{cc}
\hline Constituent & $\begin{array}{c}\text { Amount present in RH } \\
\text { (wt \%) }\end{array}$ \\
\hline$a$-cellulose & 43.30 \\
Lignin & 22.00 \\
D-xylose & 17.52 \\
L-arabinose & 6.53 \\
Methylglucuronic acid & 3.27 \\
D-galactose & 2.35 \\
\hline Total & 94.99 \\
\hline
\end{tabular}




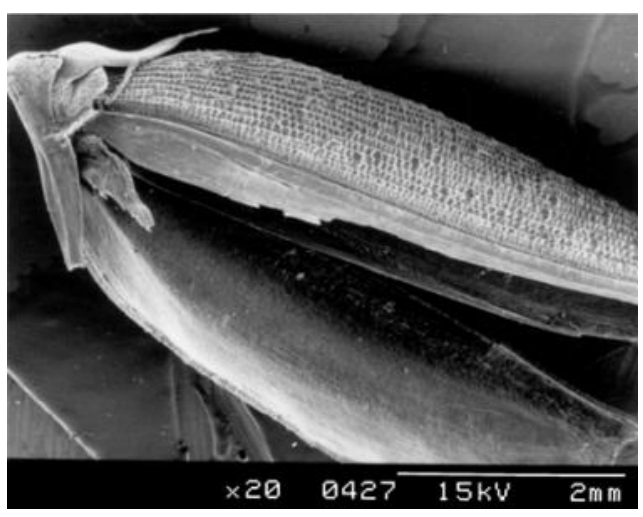

Figure 1. SEM of rice husk showing fibrous nature [10]

and potential applications in various fields are listed below:

- Non energy applications

- Incorporation in soil for composting

- Bio-fertilizer additive

- Animal husbandry low quality feed

- Sorbent material in environmental remediation

- Building material with good thermal insulation

- Pest control agent

- Board manufacturing

- Composted manure

Energy generation:

- Combustion: Heat generation, cook stoves, furnaces for heating the air in rice dryers, brick kilns, etc.

- Gasification: Gas for cook stoves, Syngas for chemicals and electricity generation.

- Pyrolysis: In research phase few commercial applications.

Burning rice husk as fuel to generate energy gives a waste product rice husk ash (RHA). About 20 million tones of RHA are produced annually in India. The fibrous nature and the small grains in $\mathrm{RH}$ do not seem to be disturbed by burning as shown in SEM of RHA (Figure 3) [11]. Chemical composition of rice husk ash is somewhat different from that of rice husk. Percentage of silica in rice husk ash increases up to $80 \%$. Ismail and Waliuddin has analyzed [12] the chemical composition of rice husk ash as given in the Table 3.

\subsection{Uses of Rice husk ash}

RHA has been used in various fields like an adsorbent, as an insulator and other application of

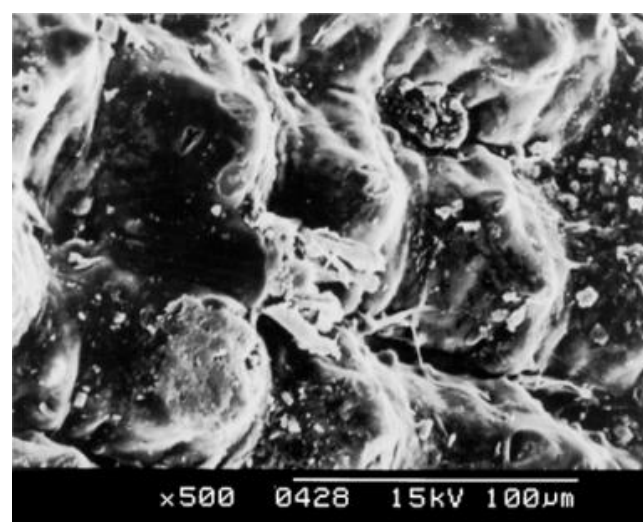

Figure 2. SEM of rice husk showing protuberance outer epidermis and silica [10]

Table 3. Chemical analysis of rice husk ash [12]

\begin{tabular}{lc}
\hline \multicolumn{1}{c}{ Constituent } & $\begin{array}{c}\text { Amount present in } \\
\text { rice husk ash (wt \%) }\end{array}$ \\
\hline Silica $\left(\mathrm{SiO}_{2}\right)$ & 80 \\
Alumina $\left(\mathrm{Al}_{2} \mathrm{O}_{3}\right)$ & 3.93 \\
Sulfur trioxide $\left(\mathrm{SO}_{3}\right)$ & 0.78 \\
Iron oxide $\left(\mathrm{Fe}_{2} \mathrm{O}_{3}\right)$ & 0.41 \\
Calcium oxide $(\mathrm{CaO})$ & 3.84 \\
Magnesium oxide $(\mathrm{MgO})$ & 0.25 \\
Sodium oxide $\left(\mathrm{Na}_{2} \mathrm{O}\right)$ & 0.67 \\
Potassium oxide $\left(\mathrm{K}_{2} \mathrm{O}\right)$ & 1.45 \\
Loss on ignition at 850 & 8.56 \\
${ }^{\circ} \mathrm{C}$ & \\
\hline
\end{tabular}

RHA [13,14] is illustrated in Table 4.

\subsection{Silica from rice husk ash}

Amorphous silica powder is basic raw material used in industries associated with rubber, ceramics, electronics, catalysis, pharmaceutics, dental material and other materials [15]. When $\mathrm{RH}$ is burnt in air, it leads to the formation of silica ash, which varies from gray to black depending upon inorganic impurities and unburnt carbon amount [16]. RHA can be obtained by burning rice husk in electric furnace at $600{ }^{\circ} \mathrm{C}$ for 4 hours [17]. Another study reported [18] that burning of $\mathrm{RH}$ $(-10 \mathrm{~mm})$ in a fluidized bed of fine sand $(0.5 \mathrm{~mm}$ diameter) with cross section of $380 \times 406 \mathrm{~mm}$ and total height of $4.8 \mathrm{~m}$. The bed temperature is maintained at $923-1173 \mathrm{~K}$, fluidizing velocity is kept $0.4-2.2 \mathrm{~m} / \mathrm{s}$, bed depth is $30-60 \mathrm{~cm}$ and excess air levels of $30-95 \%$. A proto type incinerator was designed with special features to burn rice husk 


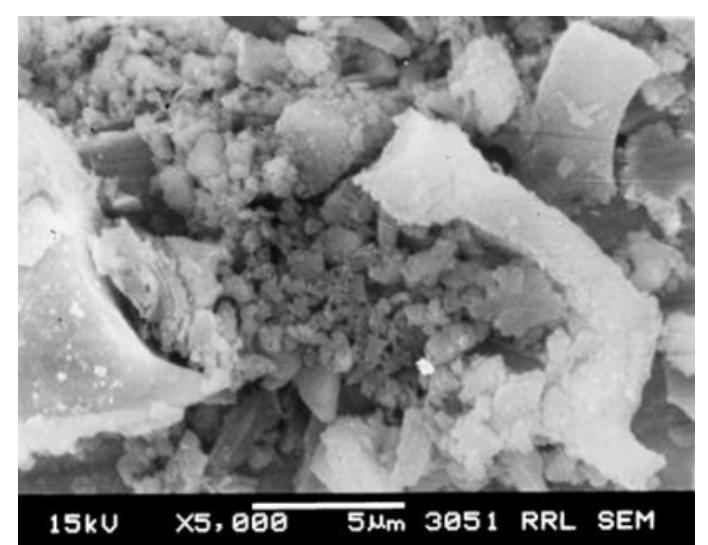

Figure 3. SEM of white ash of RH [11].

and produce amorphous and highly reactive silica [19]:

- Pure silica can be obtained from RHA by various procedures:

- Fluidized bed [20]

- Chemical pre and post treatment using acid and base solution [2]

- Pressurized hot water treatment processes [21]

- Carbonization and combustion [22]

- Non isothermal decomposition in oxidizing atmosphere [23]

A low energy method to produce pure silica (93\% with $2.6 \%$ moisture) from RHA with $91 \%$ yield was developed by Kalapathy et al., [2000]. Pure silica is obtained by dissolving RHA silica with alkali solution to form sodium silicate solution and subsequently forming silica aqua-gel by adding $\mathrm{HCl}$ to lower the $\mathrm{pH}$ from 11.8 to 7.0 followed by washing and drying to get pure silica [24]. Shelke et al. produced silica from RHA as sodium silicate source using aqueous sodium hydroxide. Silica was precipitated from sodium silicate by acidification using orthophosphoric acid. The addition of the acid was done very slowly till a $\mathrm{pH}$ of 6.5 was reached. A precipitate of white silica was obtained. The wet precipitate was dried in an oven for $24 \mathrm{~h}$ at $110^{\circ} \mathrm{C}$. Silica obtained was in form of white amorphous powder having purity $98 \%$, bulk density $1.25 \mathrm{~g} / \mathrm{ml}$ [25].

\section{Effect of temperature on burning of rice husk}

\subsection{Amorphous and Crystalline silica}

On burning rice husk, ash containing a very high percentage of crystalline silica is formed. However, if $\mathrm{RH}$ is burnt under controlled conditions, highly reactive amorphous silica is
Table 4. Uses of Rice husk ash [4,13,14]

\begin{tabular}{ll}
\hline \multicolumn{1}{c}{ Feature } & \multicolumn{1}{c}{ Application } \\
\hline Absorbent & For oils and chemicals [13, \\
Insulator & 14] As insulation powder in \\
& steel mills \\
& - In homes and refriger- \\
& ants \\
& - In the manufacture of \\
& refractory bricks \\
As a release agent in the & ceramics industry \\
Release agent & - Cement industry \\
Pozzolan & Concrete industry \\
Repellents & $\begin{array}{l}\text { As repellents in the form of } \\
\text { "vinegar-tar" }\end{array}$ \\
Aggregates and & $\begin{array}{l}\text { Aggregates and fillers for } \\
\text { concrete }\end{array}$ \\
fillers & Soil ameliorant to help \\
Soil ameliorant & break up clay soils and im- \\
& prove soil structure \\
Source of silicon & $\begin{array}{l}\text { Manufacture of industrial } \\
\text { chemicals like silica, so- } \\
\text { dium silicate, zeolite }\end{array}$ \\
& and refractory material \\
such as SiC, Si ${ }_{4}$ [4]
\end{tabular}

produced. It is observed that the ash formed at lower temperatures (773-873 K) consist of amorphous silica. Amorphous silica is one of the industrial white minerals along with china clay, $\mathrm{CaCO}_{3}$ and talc, which are used as filler in paper, paint, rubber, fertilizers and insecticides. Amorphous silica having high purity, small particle size and high surface area can be of use as an adsorbent or catalyst support in fine chemical synthesis. In order to prepare amorphous silica with high purity from rice husk, either thermal treatment [6] of the husk or treatment with various chemicals was attempted $[2,26]$ before and after combustion at temperatures ranging from 773 to $1673 \mathrm{~K}$ for different intervals of time. The chemicals included are $\mathrm{HCl}, \mathrm{H}_{2} \mathrm{SO}_{4}, \mathrm{HNO}_{3}, \mathrm{NaOH}, \mathrm{NH}_{4} \mathrm{OH}$, etc. 
Table 5. Physical properties of silica gel [3, 37]

\begin{tabular}{|c|c|c|}
\hline Property & Value & Comments \\
\hline $\begin{array}{l}\text { Thermal con- } \\
\text { ductivity }\end{array}$ & $\begin{array}{l}\sim 0.01 \\
\mathrm{~W} / \mathrm{m} . \mathrm{K}\end{array}$ & $\begin{array}{l}\text { Determined by Vac- } \\
\text { uum Insulation Con- } \\
\text { ductivity Tester }\end{array}$ \\
\hline Bulk density & $0.45 \mathrm{~g} / \mathrm{ml}$ & $\begin{array}{l}\text { Determined by using } \\
\text { Helium pincometry }\end{array}$ \\
\hline Porosity & $80 \%$ & $\begin{array}{l}\text { Determined by BET } \\
\text { method }\end{array}$ \\
\hline $\begin{array}{l}\text { Specific surface } \\
\text { area }\end{array}$ & $\begin{array}{l}142- \\
357 \mathrm{~m}^{2} / \mathrm{g}\end{array}$ & $\begin{array}{l}\text { Determined by nitro- } \\
\text { gen adsorp- } \\
\text { tion/desorption }\end{array}$ \\
\hline $\begin{array}{l}\text { Mean pore di- } \\
\text { ameter }\end{array}$ & $\sim 13 \mathrm{~nm}$ & $\begin{array}{l}\text { Determined by nitro- } \\
\text { gen adsorp- } \\
\text { tion/desorption }\end{array}$ \\
\hline $\begin{array}{l}\text { Primary parti- } \\
\text { cle diameter }\end{array}$ & $5-50 \mathrm{~nm}$ & $\begin{array}{l}\text { Determined by elec- } \\
\text { tron microscopy }\end{array}$ \\
\hline $\begin{array}{l}\text { Refractive in- } \\
\text { dex }\end{array}$ & 1.46 & $\begin{array}{l}\text { Very low for a solid } \\
\text { material }\end{array}$ \\
\hline $\begin{array}{l}\text { Dielectric con- } \\
\text { stant }\end{array}$ & $\sim 1-2$ & $\begin{array}{l}\text { Very low for a solid } \\
\text { material }\end{array}$ \\
\hline
\end{tabular}

The crystalline forms cristobalite and trydimite were detected at temperature $>1073 \mathrm{~K}$ and $>1423$ $\mathrm{K}$ respectively [27]. Crystallization of silica has to be prevented by controlling the temperature and time of burning so that maximum amorphous variety is produced. Patel et al. [6] reported that the temperature of carbonization is preferably held below $973 \mathrm{~K}$ to avoid any transformation of the amorphous phase to a crystalline form. It has been found that reheating the ash to remove carbon residues takes a relatively long period of time and somewhat higher temperatures, with the consequence that any amorphous silica is then converted to a crystalline form.

\subsection{Combustion of rice husk after leaching with acid}

It is analyzed by many authors [28] that preliminary leaching of rice husk with solution of $\mathrm{HCl}, \mathrm{HNO}_{3}, \mathrm{H}_{2} \mathrm{SO}_{4}, \mathrm{NaOH}, \mathrm{NH}_{4} \mathrm{OH}$, boiled before thermal treatment with temperature ranging from $500-1400{ }^{\circ} \mathrm{C}$, for various time intervals $[16,29]$ is effective in removing most of the metallic impurities and produces ash silica completely white in color with a high specific surface area. The ash from complete combustion of acid treated husk was white whereas that from the untreated husk under same conditions gave light brown product [30]. The acid treatment of rice husk did not affect the amorphousness of the silica. Real et al. [28] found that the preliminary leaching of $\mathrm{RH}$ with a solution of $\mathrm{HCl}$ before combustion at $600{ }^{\circ} \mathrm{C}$ could result in relatively pure silica (approximately 99.5\%) with a high specific surface area (approximately $260 \mathrm{~m}^{2} / \mathrm{g}$ ). If the leaching with $\mathrm{HCl}$ was performed on the white ashes obtained from the combustion of $\mathrm{RH}$ at $600{ }^{\circ} \mathrm{C}$, amorphous silica with the same purity was also obtained, but its specific surface area decreased to $1 \mathrm{~m}^{2} / \mathrm{g}$. The formation of black particles in the silica from untreated husk was found higher than that from acid treated husk. Potassium in the husk is responsible to cause this phenomenon, which is removed to a great extent by acid treatment [16]. Pre treatment of rice husk with $\mathrm{HNO}_{3}$ and calcination at $873 \mathrm{~K}$ is reported to give white, amorphous and chemically pure silica (98.5\%). Other acids like sulfuric, oxalic, and citric acids can also be used for leaching of rice husk but experimental results show that silica produced by hydrochloric acid possesses higher surface area than that of sulfuric, oxalic, and citric acids [31].

\section{Silica gel}

Silica gels can be prepared by the sol-gel method using a variety of starting materials as the silicon source, for example:

- Rice husk ash [32,33]

- Sodium silicate [34]

Tetraethylorthosilicate (TEOS) [33-36]. $\mathrm{SiO}_{2}$ gel made from TEOS is more expensive than that made from rice husk ash and additionally TEOS is a hazardous chemical. Further, utilization of waste rice husk ash is very attractive as value added product of silica gel.

RHA gives a yield of $73.10 \%$ means $10 \mathrm{~g}$ of it can produce $7.31 \mathrm{~g}$ of silica gel [3]. However the structure of silica present in the ash treated at 700 ${ }^{\circ} \mathrm{C}$ for $6 \mathrm{~h}$ remained essentially amorphous [27]. Typical properties of silica gel are shown below in Table 5.

\subsection{Classification of silica gel}

Silica gel is a rigid three-dimensional network of colloidal silica, and is classified as:

- Aqua-gel (pores are filled with water)

- Xero-gel (aqueous phase in the pores is removed by evaporation)

- Aero-gel (solvent is removed by supercritical extraction)

\subsection{Preparation of silica gel}

Several researchers [3, 37, 38] prepared various types of silica gels using RHA following different 


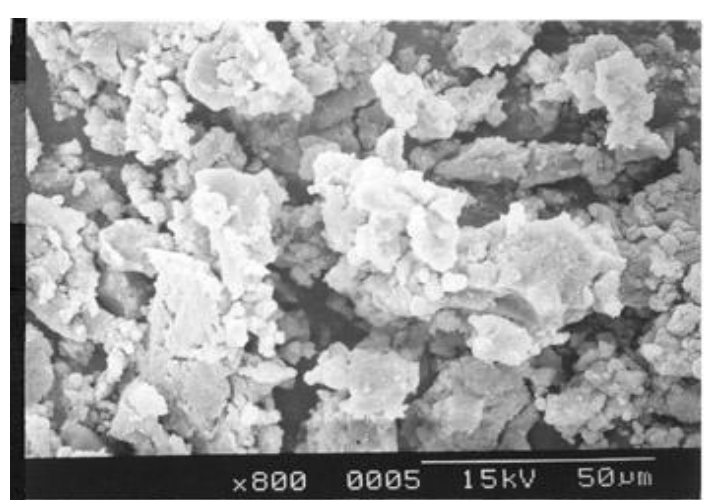

Figure 4. SEM of silica gel obtained from RHA [37]

procedures as summarized below.

Kamath et al. [37] prepared silica gel from RHA using $1 \mathrm{M}$ sulfuric acid at $\mathrm{pH}$ 7. Prepared silica gel was aged, washed, and dried under specific conditions to get a final product that was slightly basic and had a moisture content $>65 \%$. The surface area obtained was $258 \mathrm{~m}^{2} / \mathrm{g}$, the particle pore diameter was $12.1 \mathrm{~nm}$. Scanning electron micrographs revealed that rice husk silica gel particles ranged in sizes from 5-40 nm. SEM and XRD pattern of silica gel obtained are shown in the Figure 4 and in Figure 5 respectively.

A lot of improvements have done in the preparation of silica gel from rice husk. Pijarn et al. [3] prepared silica gel by the following procedure. A mixture of rice husk ash (10 g) calcined at $650{ }^{\circ} \mathrm{C}$ for $6 \mathrm{~h}$ and $1 \mathrm{M} \mathrm{NaOH}\left(320 \mathrm{~cm}^{3}\right)$ was heated under reflux for 3,5 and $9 \mathrm{~h}$. The reaction mixture was filtered via a Whatman filter paper under vacuum. Carbon residue was washed in boiled water filter $\left(200\right.$ or $\left.400 \mathrm{~cm}^{3}\right)$. The filtrate, a sodium silicate solution, was cooled to room temperature and slowly titrated against $1 \mathrm{M}$ $\mathrm{H}_{2} \mathrm{SO}_{4}$ with constant stirring. The $\mathrm{pH}$ of the solution was monitored and the titration stopped once the $\mathrm{pH}$ reached 7 . When the gel formed from the sol, it was aged for $18 \mathrm{~h}$. After aging, the gel was gently broken and the slurry was centrifuged for $5 \mathrm{~min}$ at $6000 \mathrm{rpm}$. Distilled water $\left(400 \mathrm{~cm}^{3}\right)$ was added to the gel, and the mixture gently swirled and centrifuged. The washing step was repeated 2 to 8 times. Subsequently, the gel was spread on a glass dish and dried in a vacuum oven at $80^{\circ} \mathrm{C}$. The agglomerated silica gel was then ballmilled using $\mathrm{ZrO}_{2}$ balls in plastic containers.

As the silica gel is normally white or colorless, and shows no significant change in color during use, it is difficult to tell when gel has become saturated with moisture and needs to be regenerated by heating, or replaced so there is a

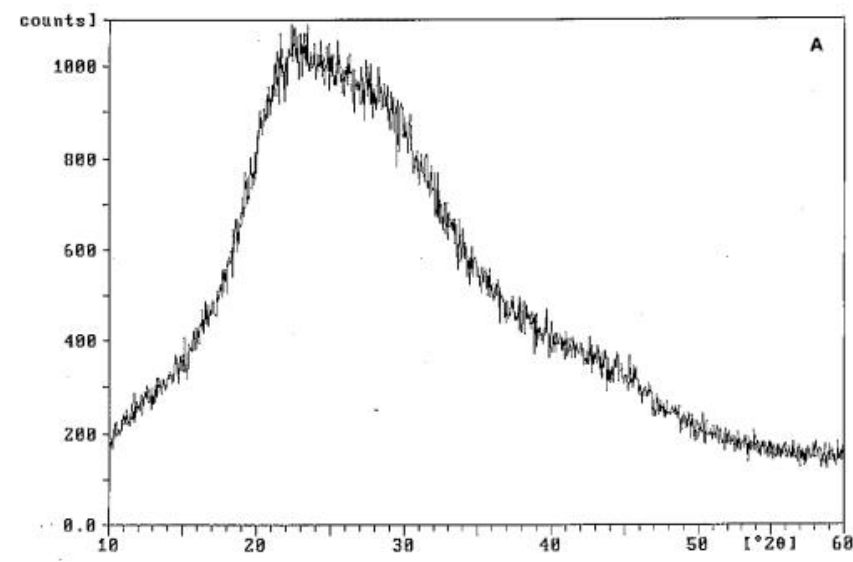

Figure 5. X-ray diffraction patterns for rice husk silica gel [37]

need for a visible indication when the gel gets saturated. Traditionally this has been achieved by immersing the gel with a cobalt salt, usually the chloride. This produces a deep blue color for the dry gel, which turns to a light pink as the gel absorbs moisture. Nayak et al. used cobalt chloride as a visible indication of the moisture content of the silica gel for determining whether the gel is saturated or not [38].

Purity of the prepared silica gel depends upon three parameters:

- Water loading by addition of boiled deionized water to silica gel solution before titration with $1 \mathrm{M} \mathrm{H}_{2} \mathrm{SO}_{4}$ acid.

- Rinse time to remove impurities in silica gel prior to the drying stage

- The reflux time for synthesis of the silica gel.

All parameters have an effect on particle size, surface area and pore size of the resulting silica gel powders [3].

\subsubsection{Condition of synthesis}

\subsubsection{Reflux time}

Pijarn et al. [3] reported that a key controlling variable for preparation of the silica gel by the solgel method is optimum reflux time. The silica gel prepared at a reflux time of $5 \mathrm{~h}$ is considered to be optimum since it has smaller particle size and the highest surface area. The $\mathrm{SiO}_{2}$ gel prepared at a reflux time of $3 \mathrm{~h}$ is considered not to be suitable since it has a bigger particle size and lower surface area when compared to $5 \mathrm{~h}$ and $9 \mathrm{~h}$ reflux time specimens. The silica gel prepared from $9 \mathrm{~h}$ reflux may have a pore volume or volume adsorption less than silica gel prepared by $5 \mathrm{~h}$ reflux due to the effect of the longer reflux time on its particle size since the $9 \mathrm{~h}$ refluxed sample is dense because of 
particle agglomeration, and the particle size is small.

\subsubsection{Rinse time}

Rinsing the silica gel twice is insufficient to remove the remnant $\mathrm{Na}_{2} \mathrm{SO}_{4}$. Rinsing more than 4 times was found to be necessary to remove the remnant $\mathrm{Na}_{2} \mathrm{SO}_{4}$ impurity. The particle size is decreased and surface area is increased when the number of rinses increased. The effect of reflux time and rinse time is shown in Figure 6 which shows the TEM of silica gel at various reflux and rinse time.

\subsection{Application of silica gel}

Due to high surface area $\left(>800 \mathrm{~m}^{2} / \mathrm{g}\right)$ of silica gel, it has a wide range of applications such as a desiccant, as a preservation tool to control humidity, as an adsorbent, as a catalyst and as a catalyst support. Silica gel is a commonly used desiccant as beads packed in a permeable bag. In many items, moisture encourages the growth of mold and spoilage. Condensation may also damage
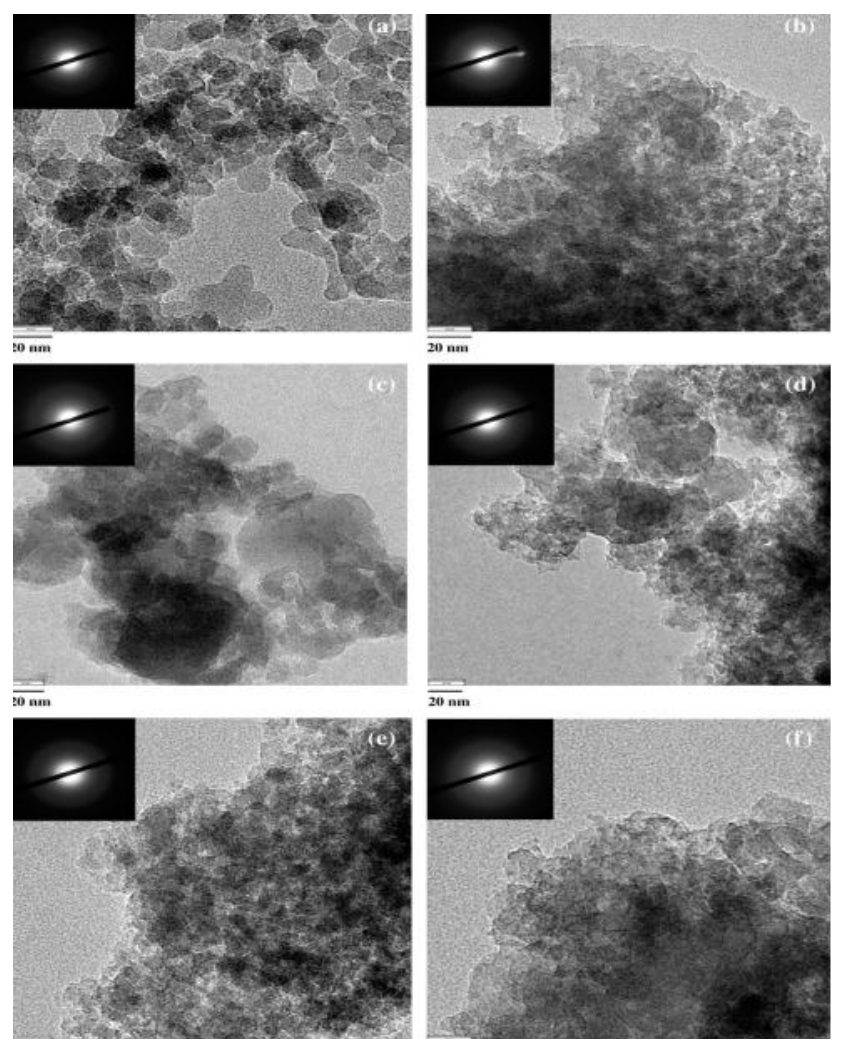

Figure 6. TEM images of $\mathrm{SiO}_{2}$ gel: (a) fumed silica (b) $\mathrm{SiO}_{2}$ gel (5 h reflux and 4 rinses), (c) $\mathrm{SiO}_{2}$ gel (5 $\mathrm{h}$ reflux and 6 rinses), (d) $\mathrm{SiO}_{2}$ gel ( $5 \mathrm{~h}$ reflux and 8 rinses), (e) $\mathrm{SiO}_{2}$ gel (9 h reflux and 8 rinses), and (f) $\mathrm{SiO}_{2}$ gel (3 h reflux and 8 rinses) [3]. other items like electronics and may speed the decomposition of chemicals. Through the inclusion of silica gel packets, these items can be preserved longer.

Silica gel may also be used to keep the relative humidity inside a high frequency radio or satellite transmission system waveguide as low as possible. It is commonly known that silica gel is used to dry the industrial compressed air and refrigerants in refrigeration systems. The silica gel absorbs moisture from the compressed air on railway locomotives, where condensation and ice in the brake air pipes can lead to brake failure.

Silica gel is sometimes used as a preservation tool to control relative humidity in museum and library exhibitions and storage. It is also used in packaging of leather products, electronic equipments, metal items, some food products, textiles, pharmaceutical products (vitamin pills) etc. Other applications of silica gel include diagnostic test strips, inhalation devices, syringes, drug test kits and hospital sanitation kits etc.

In chemistry, silica gel is used in chromatography as a stationary phase. In column chromatography, the stationary phase is most often composed of silica gel particles of 40-63 $\mu \mathrm{m}$. Different particle sizes are used for achieving a desired separation of certain molecular sizes. In this application, due to silica gel's polarity, nonpolar components tend to elute before more polar ones, hence the name normal phase chromatography. However, when hydrophobic groups (such as C18 groups) are attached to the silica gel then polar components elute first and the method is referred to as reverse phase chromatography. Silica gel is also applied to alumina, glass, or plastic sheets for thin layer chromatography.

The hydroxyl $(\mathrm{OH})$ groups on the surface of silica can be functionalized to afford specialty silica gels that exhibit unique stationary phase parameters. These so-called functionalized silica gels are also used in organic synthesis and purification as insoluble reagents and scavengers. Chelating groups have also been covalently bound to silica gel. These materials have the ability to remove metal ions selectively from aqueous media. Chelating groups can be covalently bound to polyamines that have been grafted onto a silica gel surface producing a material of greater mechanical integrity. Silica gel is also combined with alkali metals to form an M-SG reducing agent.

Silica gel is also used as cat litter by itself or in combination with more traditional materials, such as clays including bentonite. Silica in this form can 
be a cost effective way for retail consumers easily to purchase silica gel for application in such things as maintaining the desired relative humidity in humidors, keeping tools rust free in damp environments, long term storage, and preservation of dried food for long term storage. Amorphous silica powder is basic raw material used in industries associated with rubber, ceramics, electronics, catalysis, pharmaceutics, dental material and other materials [15].

\section{Silica xero-gel}

Silica xero-gel from RHA having 93\% silica and $2.6 \%$ moisture and is produced by alkaline extraction followed by acid precipitation at $\mathrm{pH} 7$ [24] and at $\mathrm{pH} 4$ with minimal mineral contaminants [38].

\subsection{Impurities Present}

The major impurities of silica produced from RHA at an extraction yield of $91 \%$ were $\mathrm{Na}, \mathrm{K}$, and Ca. Acid washing prior to extraction resulted in silica with a lower concentration of $\mathrm{Ca}(<200 \mathrm{ppm})$. However, final water washing of the xero-gel was more effective in producing silica with lower overall mineral content $(\mathrm{Na}<200 \mathrm{ppm}$ and $\mathrm{K}<400$ $\mathrm{ppm})$. Acid leaching [42] and gasification [43] methods have been investigated for recovering silica from rice husk. Silica gel produced from RHA using an alkali extraction method had over $65 \%$ moisture, $2 \%$ of sodium, $0.04 \%$ of potassium, $0.01 \%$ of calcium and traces $(<0.01 \%)$ of other elements [37]. Concentrations of $\mathrm{Na}$ and $\mathrm{K}$ in this gel were relatively high compared to $\mathrm{Na}$ and $\mathrm{K}$ concentrations in commercial silica. Hence, an effective mineral leaching step is necessary to produce xero-gels with reduced $\mathrm{Na}$ and $\mathrm{K}$ concentrations from RHA.

\subsection{Acid Washing}

The initial acid washing did not improve the purity of silica when compared to the purity of silica obtained from unwashed RHA and RHA washed at $\mathrm{pH}$ 7. Incorporation of an additional washing step after drying the extracted silica, resulted in a silica product with even lower mineral $(\mathrm{Na}$, and $\mathrm{K})$ content. Washing the dried silica (xero-gel) with deionized water is more effective than washing the silica gel (aqua-gel) prior to drying, in removing minerals from the silica. This could be due to entrapment of metal ions in the silica gel network, which may not be leached out by water washing [24]. Drying silica gel to a very low moisture level might result in disruption of the silica gel network structure and
Table 6. Physical properties of $\mathrm{SiO}_{2}$ xero-gel $[39,40$, 41]

\begin{tabular}{|c|c|c|}
\hline Properties & Value & Comments \\
\hline $\begin{array}{l}\text { Thermal con- } \\
\text { ductivity }\end{array}$ & $\begin{array}{c}\sim 0.018 \\
\mathrm{w} / \mathrm{k}\end{array}$ & $\begin{array}{l}\text { Determined by Vacuum } \\
\text { Insulation Conductivity } \\
\text { Tester }\end{array}$ \\
\hline $\begin{array}{l}\text { Bulk density } \\
(\rho)\end{array}$ & $1.19 \mathrm{~g} / \mathrm{cm}^{3}$ & $\begin{array}{l}\text { Calculated from refera- } \\
\text { ctive index by } \rho=(n- \\
1) / 0.202\end{array}$ \\
\hline $\begin{array}{l}\text { Referactive } \\
\text { index }\end{array}$ & $\sim 1.26$ & $\begin{array}{l}\text { Very low for a solid mate- } \\
\text { rial }\end{array}$ \\
\hline Porosity (П) & $47.5 \%$ & $\begin{array}{l}\Pi=1-\rho / \rho_{\mathrm{s}} \text { where } \rho_{\mathrm{s}} \\
\text { (thermally grown conven- } \\
\text { tional } \mathrm{SiO}_{2} \text { film) }\end{array}$ \\
\hline $\begin{array}{l}\text { Dielectric } \\
\text { constant }(\mathrm{k})\end{array}$ & $\sim 2.52$ & $\begin{array}{l}\text { Determined by } \\
\mathrm{k}=1+1.28 \rho,(\rho \text { is density })\end{array}$ \\
\hline Surface area & $\begin{array}{l}69-152 \\
\mathrm{~m}^{2} / \mathrm{g}\end{array}$ & $\begin{array}{l}\text { As determined by nitro- } \\
\text { gen adsorption/desorption }\end{array}$ \\
\hline Pore volume & $\begin{array}{l}0.059- \\
0.137 \\
\mathrm{~cm}^{3} / \mathrm{g}\end{array}$ & $\begin{array}{l}\text { Determined by nitrogen } \\
\text { adsorption/desorption } \\
\text { (varies with density) }\end{array}$ \\
\hline Pore diameter & $\begin{array}{l}6.4-6.8 \\
\mathrm{~nm}\end{array}$ & $\begin{array}{l}\text { Determined by nitrogen } \\
\text { adsorption/desorption } \\
\text { (varies with density) }\end{array}$ \\
\hline
\end{tabular}

would free the trapped mineral ions ( $\mathrm{Na}$, and $\mathrm{K})$. Sodium and potassium ions might be easily leached out by washing the dried gel with water. The high sodium content of xero-gel was due to the very rapid gelation at $\mathrm{pH} 7.0$ that effectively trapped sodium chloride in the gel matrix. A mixture of hydrochloric, citric and oxalic acid is used for preparation of silica. The Ca content was comparatively lower for silica prepared from acid washed RHA. This may be due to the fact that, $\mathrm{Ca}$ being the major divalent cation in RHA, will require lower $\mathrm{pH}$ washing as it is strongly adsorbed on the silica surface at $\mathrm{pH}>5$ [44]. Therefore, to keep the Ca content in silica at a lower concentration, an initial acid washing might be required.

Further, it should be noticed that the silica extraction yields were similar for unwashed RHA, RHA washed at $\mathrm{pH} 7$ and acid washed RHA. Final washing of xero-gel is necessary to keep the overall mineral content at a lower concentration. However, if a very low concentration of $\mathrm{Ca}$ is required, acid pre-wash of RHA can be used without any adverse effect on silica yield.

\subsection{Production of silica xero-gel}

Hong et al. prepared silica xero-gel with a low dielectric constant by a two-step acid-base catalyst 

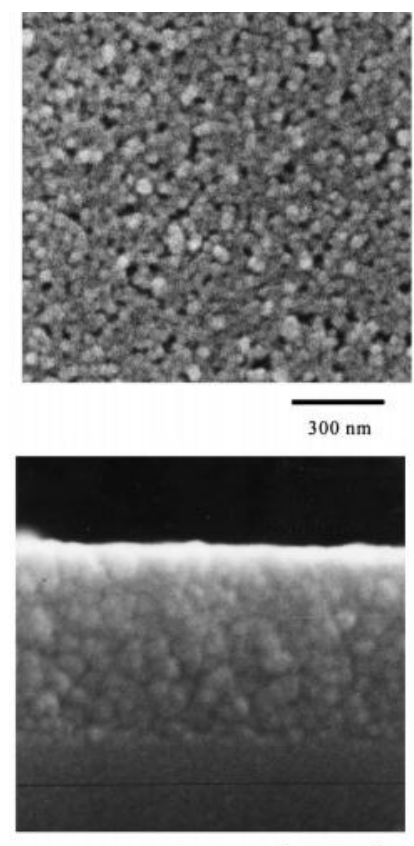

(a)

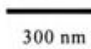

$\overline{300 \mathrm{~nm}}$

(b)
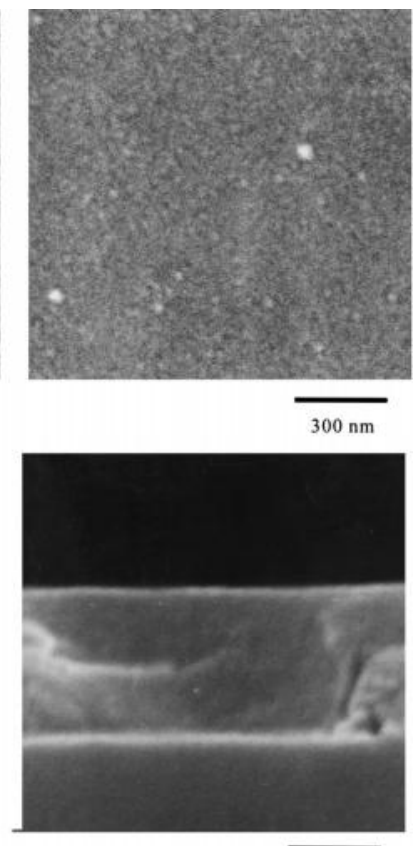

$300 \mathrm{~nm}$

Figure 7. SEM micrographs of $\mathrm{SiO}_{2}$ xero-gel films; (a) modified and (b) unmodified [41]

procedure and successive surface modification with trimethylchlorosilane (TMCS). Only $15 \%$ porosity could be obtained without surface modification but with surface modification the porosity increased to $50 \%$. The surface morphology of modified film is more porous than that of unmodified film. Unmodified film consists of very small size particles $(10 \mathrm{~nm})$ and appears to form dense $\mathrm{SiO}_{2}$ film, but modified film appears to consist of coarse $(\sim 40 \mathrm{~nm})$ particles and pores. Modified $\mathrm{SiO}_{2}$ xerogel films showed good thickness uniformity, and the average film thickness was measured as 550 $\mathrm{nm}$. This value is larger than that of unmodified film $(420 \mathrm{~nm})$ coated under the same conditions [41].

To obtain detailed information on network structure, $\mathrm{SiO}_{2}$ xero-gel dispersed in ethanol was observed using TEM. The particles shown in Figure 8 have sizes between 30 and $40 \mathrm{~nm}$ and build up a 3-dimensional network in $\mathrm{SiO}_{2}$ xero-gel film.

Kalapathy et al. has prepared silica xero-gel by adding $2 \mathrm{M}$ hydrochloric acid, $1 \mathrm{M}$ citric acid, and 1 $\mathrm{M}$ oxalic acid to $50 \mathrm{ml}$ sodium silicate solution prepared from rice husk until the $\mathrm{pH} 7.0$ was obtained and aged for 10-12 h [24]. The silica gels produced were crushed inside the beakers, dispersed in deionized water $(100 \mathrm{ml})$, and centrifuged $(1325 \mathrm{~g})$ to remove soluble salts. The washing step was repeated two more times and

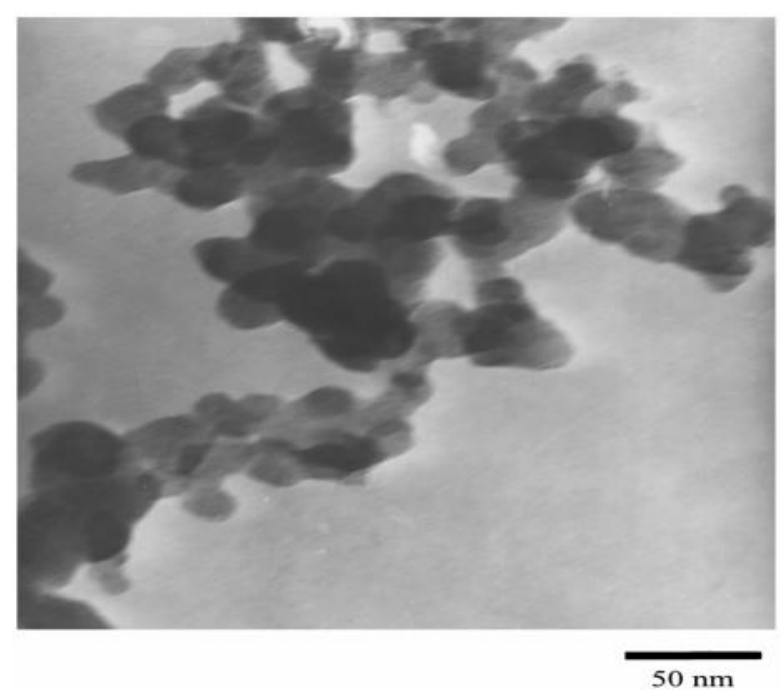

Figure 8. TEM micrograph of modified $\mathrm{SiO}_{2}$ xerogel film [41].

then dried at $80{ }^{\circ} \mathrm{C}$ for $24 \mathrm{~h}$ to obtain pure silica xero-gel [45].

\subsection{Effect of $\mathrm{pH}$ on production of silica xero- gel}

Silica gel could be produced at an acidic $\mathrm{pH}$ by adding sodium silicate to an acidic solution. This acidic solution was prepared by adding $6 \mathrm{M}$ hydrochloric acid, $3 \mathrm{M}$ citric acid, $1.5 \mathrm{M}$ oxalic acid to $100 \mathrm{ml}$ deionized water until pH 1.5 was reached then silicate solution was added to acidic solution until $\mathrm{pH}$ reached 4 . At acidic $\mathrm{pH}$, gelation is slower and hence sodium ions may diffuse out of gel matrix and can be washed out easily to produce high purity silica. It's necessary to add silicate solution to acid solution, instead of adding acid to silicate solution. When acid was added to silicate solution ( $\mathrm{pH}$ 11.8), silica gel started to form rapidly as soon as $\mathrm{pH} 10$ was reached and formed a rigid gel at $\mathrm{pH}$ 7.0. Hence it is difficult to lower the $\mathrm{pH}$ below 7.0. At $\mathrm{pH} 4.0$, gel formation was very slow and the gels were comparatively softer (as reflected by lack of firmness) than those produced at pH 7.0.

This is expected, since at $\mathrm{pH} 7.0$, covalent $\mathrm{Si}-$ $\mathrm{O}-\mathrm{Si}$ bonds were responsible for the gel structure whereas at $\mathrm{pH} 4.0$ comparatively weaker van der Waals attraction and $\mathrm{H}$-bonds were the major contributing forces for the gel structure [24]. Hence, at acidic $\mathrm{pH}$ the slower rate of gelation provided sufficient time for sodium ion and counter anions to diffuse out of the silica matrix. This diffusion process may have helped to wash out the salts effectively from aqua-gel. Furthermore, at $\mathrm{pH}$ 4.0 , the silica precipitated using citric and oxalic 


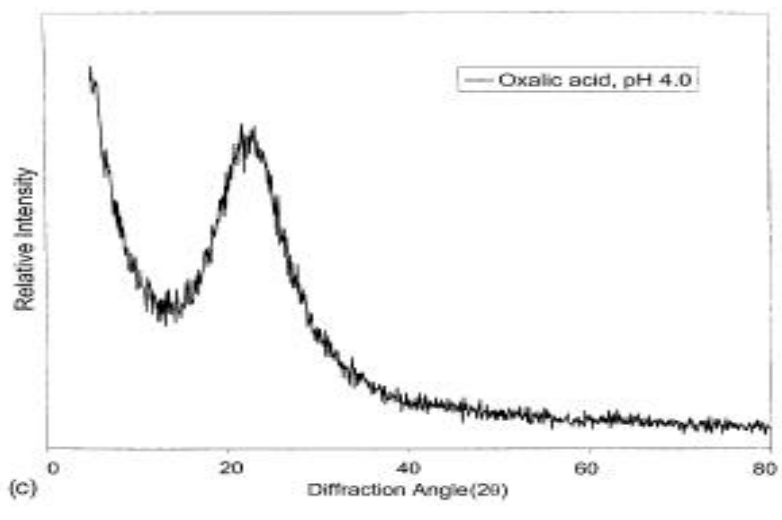

Figure 9. X-ray diffraction pattern of pure RHA silica xero-gel produced at $\mathrm{pH} 4$ using oxalic acid [45]

acid solution had lower sodium content than the silica produced using hydrochloric acid, indicating that water washing was more effective in removing sodium citrate and sodium oxalate from silica gel but not in removing sodium chloride. The XRD spectra of silica produced at $\mathrm{pH} 4.0$ using oxalic acid is shown in Figure 9 . A broad peak centered at $2 \theta$ angle of $22^{\circ}$ confirmed the amorphous nature of the silica [45].

\subsection{Silica xero-gel yield at various $\mathrm{pH}$}

No significant differences in silica yield were observed with the type of acid used for silica production or the $\mathrm{pH}$ of silica precipitation [24]. But Liou et al., reported that silica yield gradually increases with increasing $\mathrm{pH}$, with a maximum yield occurring at around $\mathrm{pH}$. When the $\mathrm{pH}$ is greater than 8, gels formed are unstable and partially redissolved. At $\mathrm{pH} 11$, these gels dissolve almost completely in water. Experimental results show that optimum conditions for producing silica are gelation at $\mathrm{pH} 3$ with a silicate concentration of $0.15 \mathrm{M}$ with an aging temperature of $50{ }^{\circ} \mathrm{C}$ and an aging time of $12 \mathrm{~h}$ [31]. Surface area of silica strongly depends on $\mathrm{pH}$ and decreases as $\mathrm{pH}$ increases.

\section{Silica Aero-gel}

The emerging sol-gel techniques from last few decades have led to a fast progress in the deliberate synthesis of porous material. Out of all known solid porous materials, Silica aero-gels have been widely accepted and used because of their low bulk density, hydrophobicity, low thermal conductivity, high surface area, optical transparency, high porosity, high specific surface area, low refractive index, low sound velocity [46, 47]. They possess a wide variety of exceptional
Table 7. Physical properties of silica aero-gel [48, 49]

\begin{tabular}{|c|c|c|}
\hline Property & Value & Comments \\
\hline $\begin{array}{l}\text { Thermal conductiv- } \\
\text { ity }\end{array}$ & $\sim 0.01 \mathrm{~W} / \mathrm{m} . \mathrm{K}$ & $\begin{array}{l}\text { Determined by Vacuum } \\
\text { Insulation Conductivity } \\
\text { Tester }\end{array}$ \\
\hline Bulk density & $\begin{array}{l}\sim 0.03-0.35 \\
\mathrm{gm} / \mathrm{cm}^{3}\end{array}$ & $\begin{array}{l}\text { Most common density is } \\
\sim 0.1 \mathrm{~g} / \mathrm{cm}^{3} \text { and deter- } \\
\text { mined by using Helium } \\
\text { pincometry }\end{array}$ \\
\hline Porosity & $\sim 99 \%$ & $\begin{array}{l}\text { As determined by BET } \\
\text { method }\end{array}$ \\
\hline $\begin{array}{l}\text { Optical transmis- } \\
\text { sion }\end{array}$ & $99 \%$ & $\begin{array}{l}\text { Determined by Rayleigh } \\
\text { scattering theory }\end{array}$ \\
\hline $\begin{array}{l}\text { Specific surface } \\
\text { area }\end{array}$ & $\begin{array}{l}600-1200 \\
\mathrm{~m}^{2} / \mathrm{g}\end{array}$ & $\begin{array}{l}\text { As determined by nitro- } \\
\text { gen adsorp- } \\
\text { tion/desorption }\end{array}$ \\
\hline Sound velocity & $100 \mathrm{~m} / \mathrm{s}$ & $\begin{array}{l}\text { For density }=0.07 \mathrm{~g} / \mathrm{cm}^{3} \text {. } \\
\text { One of the lowest veloci- } \\
\text { ties for a solid material }\end{array}$ \\
\hline$\%$ Solids & $0.13-15 \%$ & $\begin{array}{l}\text { Typically 5\% (95\% free } \\
\text { space) }\end{array}$ \\
\hline Mean pore diameter & $\sim 20 \mathrm{~nm}$ & $\begin{array}{l}\text { Determined by nitrogen } \\
\text { adsorption/desorption } \\
\text { (varies with density) }\end{array}$ \\
\hline $\begin{array}{l}\text { Primary particle } \\
\text { diameter }\end{array}$ & $2-5 \mathrm{~nm}$ & $\begin{array}{l}\text { Determined by electron } \\
\text { microscopy }\end{array}$ \\
\hline $\begin{array}{l}\text { Coefficient of ther- } \\
\text { mal expansion }\end{array}$ & $\begin{array}{l}2.0-4.0 \times \\
10^{-6}\end{array}$ & $\begin{array}{l}\text { Determined using ultra- } \\
\text { sonic methods }\end{array}$ \\
\hline Refractive index & $\sim 1.05$ & $\begin{array}{l}\text { Very low for a solid ma- } \\
\text { terial }\end{array}$ \\
\hline Dielectric constant & $\sim 1.0-2.0$ & $\begin{array}{l}\text { For density }=0.1 \\
\mathrm{~g} / \mathrm{cm}^{3} \text {.Very low for a solid } \\
\text { material }\end{array}$ \\
\hline
\end{tabular}

properties as listed in the Table 7 .

Many authors have studied the synthesis of silica aero-gels by the use of different precursors and many have focused on modification of synthesis parameters [50,51]. Recently many research works have been devoted to ambient pressure drying which makes the production commercial and industrial [50, 52, 53]. Aero-gels are synthesized from molecular precursor by solgel processing. Pore liquid is replaced with air while maintaining the solid network. Special drying techniques are adapted. Supercritical drying is most common however recently adapted techniques involve removal of liquid at atmospheric pressure after chemical modification of inner surface of gels leaving a porous silica network filled with air [48].

\subsection{Properties of silica aero-gels and methods of determination}

Extensive interest in aero-gels, particularly silica aero-gels, is due to their unusual solid 
Table 7. Physical properties of silica aero-gel $[48,49]$

\begin{tabular}{|c|c|c|}
\hline Property & Value & Comments \\
\hline $\begin{array}{l}\text { Thermal conduc- } \\
\text { tivity }\end{array}$ & $\sim 0.01 \mathrm{~W} / \mathrm{m} . \mathrm{K}$ & $\begin{array}{l}\text { Determined by Vac- } \\
\text { uum Insulation } \\
\text { Conductivity Tester }\end{array}$ \\
\hline Bulk density & $\begin{array}{l}\sim 0.03-0.35 \\
\mathrm{gm} / \mathrm{cm}^{3}\end{array}$ & $\begin{array}{l}\text { Most common den- } \\
\text { sity is } \sim 0.1 \mathrm{~g} / \mathrm{cm}^{3} \\
\text { and determined by } \\
\text { using Helium pin- } \\
\text { cometry }\end{array}$ \\
\hline Porosity & $\sim 99 \%$ & $\begin{array}{l}\text { As determined by } \\
\text { BET method }\end{array}$ \\
\hline $\begin{array}{l}\text { Optical transmis- } \\
\text { sion }\end{array}$ & $99 \%$ & $\begin{array}{l}\text { Determined by } \\
\text { Rayleigh scattering } \\
\text { theory }\end{array}$ \\
\hline $\begin{array}{l}\text { Specific surface } \\
\text { area }\end{array}$ & $\begin{array}{l}600-1200 \\
\mathrm{~m}^{2} / \mathrm{g}\end{array}$ & $\begin{array}{l}\text { As determined by } \\
\text { nitrogen adsorp- } \\
\text { tion/desorption }\end{array}$ \\
\hline Sound velocity & $100 \mathrm{~m} / \mathrm{s}$ & $\begin{array}{l}\text { For density }=0.07 \\
\text { g/cm }{ }^{3} \text {. One of the } \\
\text { lowest velocities for } \\
\text { a solid material }\end{array}$ \\
\hline$\%$ Solids & $0.13-15 \%$ & $\begin{array}{l}\text { Typically } 5 \%(95 \% \\
\text { free space) }\end{array}$ \\
\hline $\begin{array}{l}\text { Mean pore diame- } \\
\text { ter }\end{array}$ & $\sim 20 \mathrm{~nm}$ & $\begin{array}{l}\text { Determined by ni- } \\
\text { trogen adsorp- } \\
\text { tion/desorption } \\
\text { (varies with density) }\end{array}$ \\
\hline $\begin{array}{l}\text { Primary particle } \\
\text { diameter }\end{array}$ & $2-5 \mathrm{~nm}$ & $\begin{array}{l}\text { Determined by elec- } \\
\text { tron microscopy }\end{array}$ \\
\hline $\begin{array}{l}\text { Coefficient of ther- } \\
\text { mal expansion }\end{array}$ & $2.0-4.0 \times 10^{-6}$ & $\begin{array}{l}\text { Determined using } \\
\text { ultrasonic methods }\end{array}$ \\
\hline Refractive index & $\sim 1.05$ & $\begin{array}{l}\text { Very low for a solid } \\
\text { material }\end{array}$ \\
\hline Dielectric constant & $\sim 1.0-2.0$ & $\begin{array}{l}\text { For density }=0.1 \\
\mathrm{~g} / \mathrm{cm}^{3} \text {. Very low for a } \\
\text { solid material }\end{array}$ \\
\hline
\end{tabular}

material properties which are described below:

\subsubsection{Pore Structure}

According to IUPAC classification for porous materials, the pores are classified on the basis of size:

- Micropores: pores having diameters $<2 \mathrm{~nm}$

- Mesopores: pores having diameters between 2 $50 \mathrm{~nm}$

- Macropores: pores having diameters $>50 \mathrm{~nm}$

Silica aero-gels possess pores of all three sizes [54]. The approximate values of the pore size are between 5 and $100 \mathrm{~nm}$, with an average pore diameter between 20 and $40 \mathrm{~nm}$ and a BET surface area between 600 and $1000 \mathrm{~m}^{2}$. Porosity can be as high as $99 \%$.

Aero-gel pore network has an "open" nature and interconnectivity. In open-pore structures,

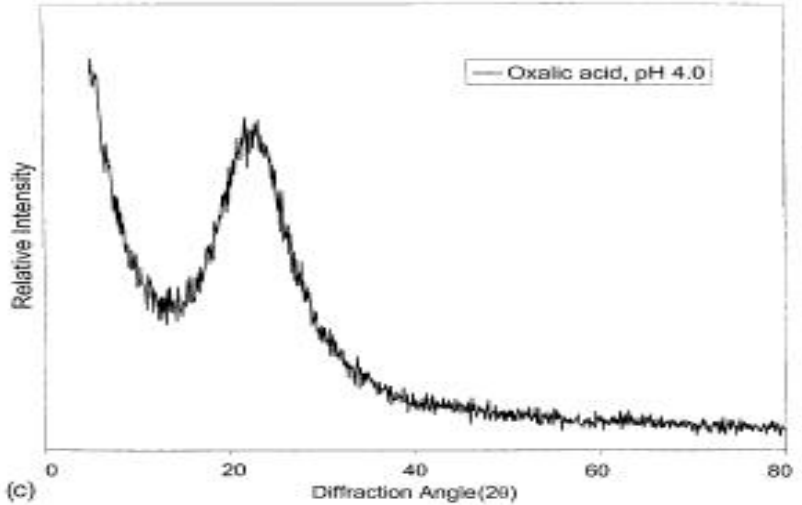

Figure 9. X-ray diffraction pattern of pure RHA silica xero-gel produced at $\mathrm{pH} 4$ using oxalic acid [45]

however, fluid flows from pore to pore, with limited restriction, and travel through the entire material. These pore structures of silica aero-gels, lead to applications as catalyst [55], absorbing media for desiccation [56, 57] and waste containment [58]. Aero-gels have an unusual combination of high porosity and small pore size. The most widely used method for determination of aero-gel porosity is the nitrogen adsorption/desorption technique [59-61]. In this method, the amount of adsorbed gas is measured [62]. Nitrogen-adsorption techniques can, in principle, distinguish various pore shapes by the shape of the isotherms. However, apart from experimental deficiencies [63], the shapes of aero-gel isotherms are very similar. The microstructure of aero-gels can be determined by high resolution scanning electron microscopy (SEM) and transmission electron microscopy (TEM) as shown in the Figure 10 [64].

\subsubsection{Density}

Volume shrinkage of the aero-gels is calculated from the volumes of the hydro-gel and aero-gel. Two different terms are used to characterize silica aero-gels: bulk density and skeletal density.

- Bulk density $\left(\rho_{b}\right)$ is defined as the ratio of the aero-gel's mass to its volume. This density is obtained by mass and $\mathrm{Hg}$-displacement volume at atmospheric pressure.

- The texture of the solid part of aero-gels is made of ultra fine particles. Skeletal density of these particles is supposed to be very close to that of the solid and it is obtained by using helium picnometry [65].

\subsubsection{Optical Properties}

In many procedures, the resulted silica aero- 

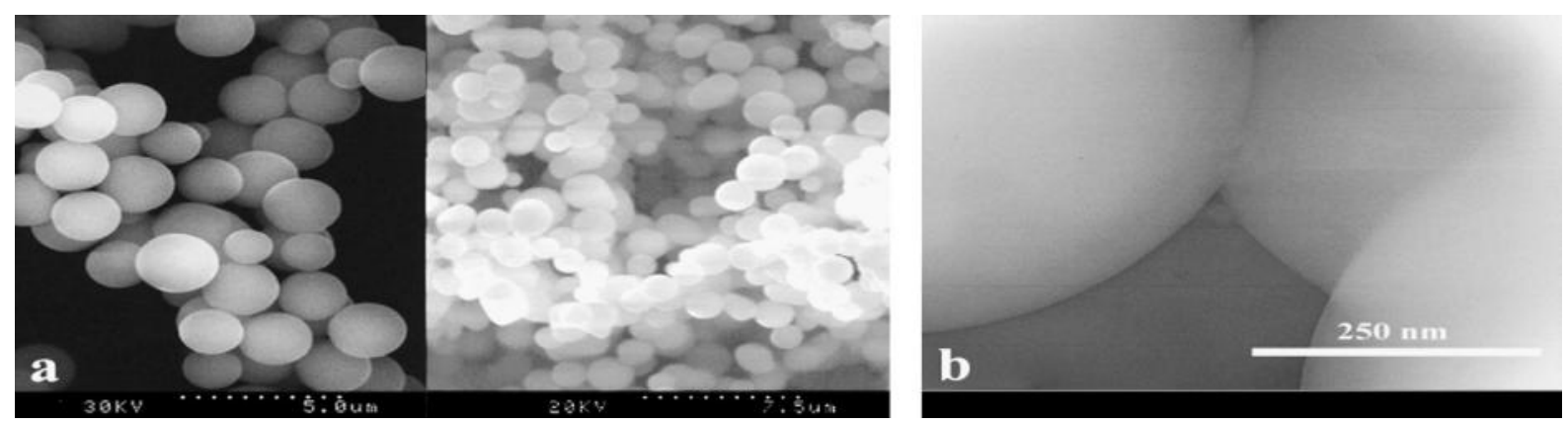

Figure 10. (a) SEM (b) TEM picture, showing the pore characteristics of silica aero-gels [64]

gels are transparent and it is an unusual property for a porous material. This relatively rare combination of traits arises because the aero-gel microstructure has a scale small compared to the wavelength of light. Aero-gels are transparent because there is a small amount of scattering in the visible, the scattered light has a relatively isotropic angular distribution, and exhibits little multiple scattering [66,67]. This behavior can be described by Rayleigh scattering theory. Due to their very high thermal insulation properties and their optical transparency in the visible region, aero-gels were proposed for double plane windows $[68,69]$. Heating the aero-gels improves their transparency due to desorption of water and burning of organic components [70]. Also, the optical properties of aero-gels are greatly influenced by the sol-gel process parameters and the type of silation agent [71].

\subsubsection{Thermal Conductivity}

Silica aero-gels are highly insulating materials having thermal conductivity lower than still air because of their porosity and nanometer pore size. Kistler [19,32] demonstrated that the thermal conductivity of an aero-gel is approximately 0.02 $\mathrm{W} / \mathrm{mK}$ at ambient pressure in air and in the order of $0.01 \mathrm{~W} / \mathrm{mK}$ when evacuated [72]. Because silica aero-gels have a very small $(\sim 1-10 \%)$ fraction of solid silica, thus exhibit a lower solid conductivity and hence, transmit a lower thermal energy. The final mode of thermal transport through silica aero-gels is infrared radiation. The optical thickness of the sample is an important parameter that influences this transfer route and is given as the product of the geometrical thickness and the optical extinction coefficient of the aero-gel. At low temperatures, the radiative component of thermal transport is low, but at higher temperatures, radiative transport becomes a dominant mode of thermal conduction. For measurement of the thermal conductivity, a Vacuum Insulation
Conductivity Tester - VICTOR - may be employed. Some authors reported the use of a hot wire method [73].

\subsubsection{Hydrophobicity}

Depending on the conditions during synthesis, silica aero-gels can either be hydrophilic or hydrophobic. The main source of hydrophilicity is silanol polar groups $\mathrm{Si}-\mathrm{OH}$ present in the aero-gel structure, because they can promote the adsorption of water. Generally, aero-gels synthesized by unmodified hydrolysis and condensation of alkylorthosilicates and dried by high temperature supercritical drying (HTSCD) are hydrophobic, and those dried by $\mathrm{CO}_{2}$ are hydrophilic. This difference is due to the different surface groups formed during the supercritical drying (SCD) process. Low temperature supercritical drying (LTSCD) results in hydroxyl groups $(-\mathrm{OH})$ on the surface resulting hydrophilic aero-gels. HTSCD allows for the reaction of the surface hydroxyl groups with the solvent to form methoxy groups $\left(-\mathrm{OCH}_{3}\right) \mathrm{X}$ and thus results in hydrophobic aero-gels. Fourier transform infrared spectroscopy (FTIR) is employed to investigate the chemical bonding state of aero-gels [74].

There are two different routes to increase the hydrophobicity of an aero-gel:

- By the addition of a silylating agent during the sol-gel step. This principle is used in ambient pressure drying methods [75].

- By the modification of the aero-gel surface after drying. The surface of hydrophilic aero-gels can be modified by reaction with gaseous methanol [73].

The hydrophobicity of the aero-gels is tested by measuring the contact angle $\theta$, of a water droplet with the aero-gel surface using the formula (1),

$$
\theta=2 \tan ^{-1}(2 h / w)
$$

Where $h$ is the height and $w$ is the width of the 
Table 8. Application of silica aero-gel $[48,76,77]$

\begin{tabular}{|c|c|c|}
\hline Property & Features & Applications \\
\hline $\begin{array}{l}\text { Thermal conductiv- } \\
\text { ity }\end{array}$ & $\begin{array}{l}\text { 1) Highly Insulating solid } \\
\text { 2) Low thermal conductivity } \\
\text { 3) Withstand high temperature } \\
\text { 4) Transmit lower thermal energy }\end{array}$ & $\begin{array}{l}\text { 1) Building construction and appliance insu-lation } \\
\text { 2) Storage media } \\
\text { 3) Automobiles, Space vehicles } \\
\text { 4) Solar devices, Solar ponds } \\
\text { 5) Refrigerator } \\
\text { 6) Thermal insulation material for windows }\end{array}$ \\
\hline Density/ porosity & $\begin{array}{l}\text { 1) Lightest } \\
\text { synthetic solid } \\
\text { 2) High surface area } \\
\text { 3) Multiple Compo-sitions } \\
\text { 4) Low bulk density }\end{array}$ & $\begin{array}{l}\text { 1) Catalysis } \\
\text { 2) Sensor } \\
\text { 3) Fuel storage } \\
\text { 4) Ion exchange } \\
\text { 5) Filters for pollutants gaseous } \\
\text { 6) Absorbing media for desiccation } \\
\text { 7) Waste containment }\end{array}$ \\
\hline Optical & $\begin{array}{l}\text { 1) Transparent } \\
\text { 2) Low refractive index }\end{array}$ & $\begin{array}{l}\text { 1) Light weight optics } \\
\text { 2) Light guides }\end{array}$ \\
\hline Acoustic & Low speed of sound & $\begin{array}{l}\text { 1) Sound proof rooms } \\
\text { 2) Acoustic impedance matching in ultrasonic } \\
\text { distance sensors }\end{array}$ \\
\hline Mechanical & $\begin{array}{l}\text { 1) Elastic } \\
\text { 2) Light weight }\end{array}$ & $\begin{array}{l}\text { 1) Energy absorber } \\
\text { 2) Hypervelocity particle trap }\end{array}$ \\
\hline Electrical & $\begin{array}{l}\text { 1) Lowest dielectric constant } \\
\text { 2) High dielectric strength } \\
\text { 3) High surface area }\end{array}$ & $\begin{array}{l}\text { 1) Dielectrics for ICs } \\
\text { 2) Spacers for vacuum electrodes } \\
\text { 3) Capacitors } \\
\text { 4) Cherenkov detectors }\end{array}$ \\
\hline Chemical & $\begin{array}{l}\text { 1)Good adsorbent } \\
\text { 2) High surface area }\end{array}$ & $\begin{array}{l}\text { 1) Adsorbent } \\
\text { 2) Catalyst support } \\
\text { 3) Extracting agent } \\
\text { 4) Nano vessels }\end{array}$ \\
\hline Filler & Thickening agent & $\begin{array}{l}\text { 1) Paints } \\
\text { 2) Varnishes } \\
\text { 3) Functional liquid }\end{array}$ \\
\hline
\end{tabular}

water droplet touching the aero-gel surface. The retention of hydrophobi-city is judged from the absorption of water by the aero-gels. Hydrophobic gels exhibit hydrophobicity only for a certain period of time.

\subsection{Application of silica aero-gel}

Commercial applications of silica aero-gel in thermal window insulation, acoustic barriers, supercapacitors and catalytic supports have been proposed, [76-80]. However, monolithic silica aerogel has been used extensively in high energy physics in Cherenkov radiation detectors [81-85]. Other application of silica aero-gels are in shock wave studies at high pressures, inertial confinement fusion (ICF) [86], radioluminescent devices [87] and micrometeorites [88]. Silica aerogels have been widely accepted and used (Table 8) because of their exceptional properties discussed above.

\subsection{Synthesis of silica aero-gel}

The synthesis of silica aero-gels can be divided into 3 general steps:

\section{a) Gel preparation}

The silica gel is obtained by sol-gel process. The sol is prepared by a silica source solution and gelation is occurred by the addition of a catalyst.

\section{b) Aging of the gel}

The gel prepared in the first step is aged in its mother solution. This aging process strengthens the gel, so that shrinkage during the drying step is kept to a minimum. Increasing the aging time from 1 to $12 \mathrm{~h}$ causes a considerable increase in sample surface area. Further, increasing aging times from 12 to $96 \mathrm{~h}$ can cause reduction in surface area [31]. Increasing aging temperature from 20 to $50{ }^{\circ} \mathrm{C}$ increases surface area due to accelerated growth of silica framework with increasing aging 
temperature. However, when aging temperature increases from 50 to $120^{\circ} \mathrm{C}$, surface area decreases because gelation rate is faster at high formation temperature.

\section{c) Drying of the gel}

In this step, the gel should be freed of the pore liquid. To prevent the collapse of the gel structure drying is made to take place under special conditions as described below.

\subsubsection{Silica aero-gel production by supercritical carbon dioxide drying}

In supercritical drying (SCD) method, the pore liquid is removed above the Critical Temperature $\left(\mathrm{T}_{\mathrm{c}}\right)$ and Critical Pressure $\left(\mathrm{P}_{\mathrm{c}}\right)$ of the concerned liquid. At this point there is no liquid-vapour interface and, thus, no capillary pressure [89]. There are two different methods of supercritical drying: - High temperature supercritical drying
(HTSCD)

- Low temperature supercritical drying (LTSCD)

\subsubsection{High temperature supercritical drying (HTSCD)}

HTSCD method is the first method of drying the silica aero-gel. Kistler in 1931 used this method for silica aero-gel production and from then it is being used for the same [72]. Nicolaon and Teichner, [19001906, 1968] prepared silica aero-gels by high temperature supercritical drying of a wet gel produced by the hydrolysis of TMOS in methanol [90].

TSCD is done in three steps as follows:

- Silica gel having sufficient amount of solvent (e.g. methanol) is placed in an autoclave and the temperature is raised slowly. Due to this pressure increases. Both the temperature and pressure are adjusted to reach values above the critical points of the corresponding solvent. The conditions are kept constant for a certain period of time when the set temperature and pressure is reached.

- The fluid is then slowly vented at constant temperature, resulting in a pressure drop.

- On attaining the ambient pressure, the vessel is cooled to room temperature. Thus, the phase boundary between liquid and gas is not crossed during the drying process. HTSCD is schematically represented in Figure 11.

Supercritical drying in organic liquids leads to rearrangement reactions in the gel network due to

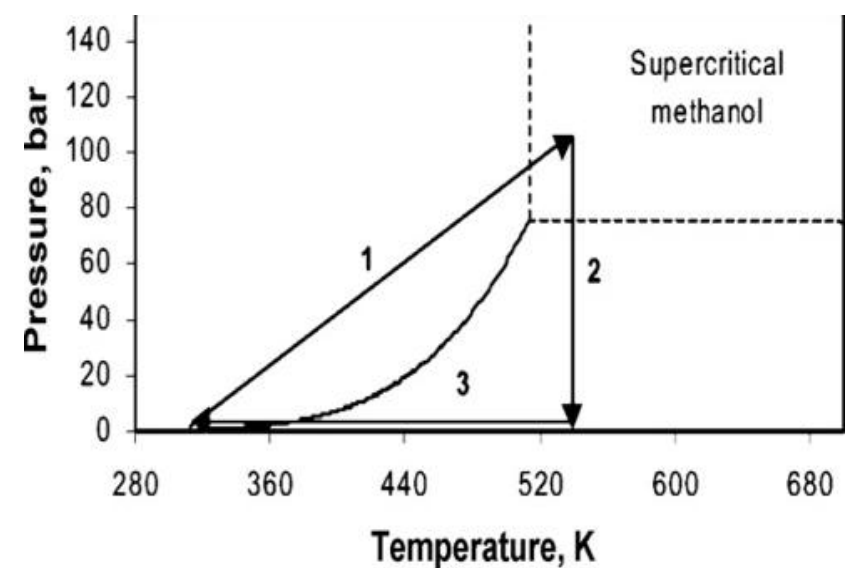

Figure 11. Schematic procedure of high temperature supercritical drying [49]

high temperature conditions. For example, under supercritical conditions, the silica aero-gel surface is reesterified, making the material hydrophobic and stable when exposed to atmospheric moisture.

Poco et al. [91] developed a rapid supercritical extraction (RSCE) for SCD and then further used by [92-94]. In RSCE, rates of condensation reactions were increased due to the increased temperature. Sol was poured directly into a container and heated immediately to supercritical conditions in an autoclave. Gelation and aging occurred during heating and the reaction rates were found to be very high because of high temperatures. Also, the gel filled the container completely, which enabled relatively fast venting of the supercritical fluid. This process seems to be a modification of normal high temperature drying. This method, however, may present problems due to the combination of high temperatures and high pressures as well as the flammability of the solvents.

Many efforts have been carried out for establishing a drying procedure that can be done at moderate temperatures and pressures. Kirkbir et al. observed that a threshold pressure exists above which the shrinkage is negligible. Below the threshold point, the capillary pressure overcomes the strength and the structure collapses. The threshold point depends on sol composition. They managed to reduce the drying pressure (but not the temperature). Several different solvents such as ethanol, butanol, pentanol and isooctane were tested and, in each case, it was found that the drying pressure could be reduced to a certain value, so that shrinkage of the aero-gels did not exceed 5\%. They found that shrinkage is negligible 


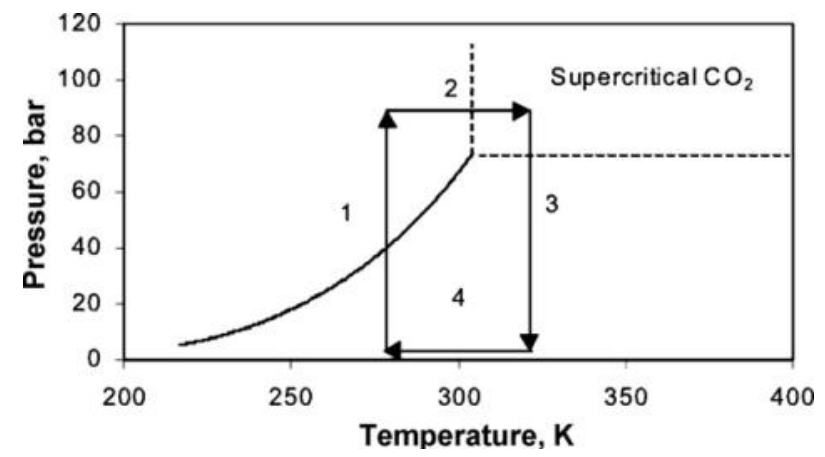

Figure 12. Schematic procedure of low temperature supercritical drying [49]

for wet gels dried in 2-pentanol at 1.8 $\mathrm{MPa}$ and 300 ${ }^{0} \mathrm{C}$ [95].

\subsubsection{Low temperature supercritical drying (LTSCD)}

Tewari et al. [96] reported an alternative method for drying of silica aero-gel. The solvent present in the gel before drying (generally alcohol) is replaced by a liquid having a critical point close to ambient temperature. The most practical choice is liquid $\mathrm{CO}_{2}$. LTSCD has the advantage of being implemented at a low temperature $\left(<40{ }^{\circ} \mathrm{C}\right)$ and moderate pressure $(<80 \mathrm{bar})$. The whole process is shown schematically in Figure 12.

The experimental procedure has the following steps:

- The gel containing excess amount of solvent (e.g. $\mathrm{CH}_{3} \mathrm{OH}$ ) is placed in an autoclave. The vessel is sealed and liquid $\mathrm{CO}_{2}$ is pumped in at $4-10{ }^{\circ} \mathrm{C}$ until the pressure reaches about 100 bar. Then the outlet valve is opened so that the solvent extracted by the liquid $\mathrm{CO}_{2}$, is able to flow out. When $\mathrm{CO}_{2}$ replaces the solvent completely, the pump is turned off; the temperature is raised to $40{ }^{\circ} \mathrm{C}$ (i.e. above the critical temperature of $\mathrm{CO}_{2}, \mathrm{Tc}=31{ }^{\circ} \mathrm{C}$ ) and the pressure is kept constant at 100 bar.

- On reaching $40{ }^{\circ} \mathrm{C}$, and thus ensuring the transition of $\mathrm{CO}_{2}$ into the supercritical state, the system is slowly depressurized under natural flow.

- When ambient pressure is reached, the system is cooled down to the room temperature. Aerogels obtained by this method are hydrophilic.

After ten years, a modification in LTSCD process was done such as to involve the use of supercritical $\mathrm{CO}_{2}$ in place of liquid $\mathrm{CO}_{2}$. In this process, the heating and cooling steps can be eliminated. The LTSCD process also involves an extraction step, which strongly depends on the diffusion of $\mathrm{CO}_{2}$ in the solvent. The LTSCD process has an extraction step, which strongly depends on the diffusion of $\mathrm{CO}_{2}$ in the solvent. The transport mechanisms of alcohol and $\mathrm{CO}_{2}$ are described by Knudsen and surface diffusion [95]. The duration of the drying step is difficult to predict, because in most cases the diffusion coefficients of the liquid in the sample are unknown. In order to describe the extraction process, Novak et al. determined binary diffusion coefficients of methanol-liquid $\mathrm{CO}_{2}$ and methanol-supercritical $\mathrm{CO}_{2}$.

They found that the diffusion coefficient increases with increasing temperature. But in lowtemperature aero-gel production, replacement of an original solvent with liquid or supercritical carbon dioxide is the critical stage and is fully controlled by diffusional mechanism [97]. Wawrzyniak et al. proposed the variation of the effective diffusion coefficient of ethanol in the vicinity of the critical point of $\mathrm{CO}_{2}$ [98]. But in lowtemperature aero-gel production, replacement of an original solvent with liquid or supercritical carbon dioxide is the critical stage and it is one fully controlled by diffusion mechanism. In order to describe the extraction process, binary diffusion coefficients of methanol-liquid $\mathrm{CO}_{2}$ and methanolsupercritical $\mathrm{CO}_{2}$ were determined by [97]. They found that the diffusion coefficient increases with increasing temperature.

\subsubsection{Comparison of HTSCD and LTSCD}

Ehrburger-Dolle et al. performed a comparative study of resulted aero-gels dried by HTSCD and LTSCD methods. They reported that the micro porosity of $\mathrm{CO}_{2}$-dried aero-gels is significantly larger than that of the corresponding $\mathrm{MeOH}$-dried aero-gels [99]. However, the micro and mesoporous textures of the $\mathrm{CO}_{2}$-dried aero-gel are equivalent to those of the alco-gel [100]. Dieudonne et al. [101] illustrated by small- angle X-ray scattering (SAXS) experiments, that the aero-gels obtained by $\mathrm{CO}_{2}$ dried aero-gels have tough solid particles whereas methanol supercritical drying show a smooth surface. However, transparency of the $\mathrm{CO}_{2}$-dried samples is comparable with that of alcohol-dried samples [96]. Tajiri and Igarashi also studied [102] the transmittance of aero-gels, dried in different supercritical media and gave the same result. It was reported, that for the HTSCD, isopropanol seems to be the most favored medium.

Tang and Wang [17] prepared silica aero-gel from rice husk by the following procedure. First of all, rice husk was burned at $600{ }^{\circ} \mathrm{C}$ for $4 \mathrm{hr}$ in 
electric furnace to get rice husk ash. A $1.5 \mathrm{~g}$ of the ash was mixed with $50 \mathrm{ml} 1 \mathrm{~mol} / \mathrm{L} \mathrm{NaOH}$ aqueous solution. The mixture was heated up to its boiling point for $1.5 \mathrm{~h}$ with the reflux. After reflux, the mixture was filtered to remove the residues and the filtrate was neutralized using $1 \mathrm{~mol} / \mathrm{L}$ sulfuric acid to $\mathrm{pH}=7$ to form silica hydro gel. The ageing of prepared gel was done for $24 \mathrm{hr}$ at room temp. The aged gel was washed using de-ionized water to remove the sodium sulfate resulted from the neutralization. Subsequently, the water in the silica gel was replaced by nonhydrous ethanol. After that, the pretreated silica gel was ready for the supercritical drying.

For supercritical drying, the prepared silica gel sample of about $5 \mathrm{~cm}^{3}$ volume was put into the extraction autoclave, which had a volume of $50 \mathrm{ml}$. The autoclave was pressurized with $\mathrm{CO}_{2}$ up to $16 \mathrm{MPa}$ at $25^{\circ} \mathrm{C}$ for $24 \mathrm{~h}$. During this period, the ethanol in the silica gel was replaced by liquid $\mathrm{CO}_{2}$. Then the autoclave was heated to $40{ }^{\circ} \mathrm{C}$ with constant pressure at $16 \mathrm{MPa}$. Dynamic drying was performed with $\mathrm{CO}_{2}$ flow rate of $1.5 \mathrm{~mol} / \mathrm{h}$ for $4 \mathrm{~h}$ at $40{ }^{\circ} \mathrm{C}$ and $16 \mathrm{MPa}$. Afterwards, the autoclave was slowly depressurized to atmosphere at $40{ }^{\circ} \mathrm{C}$. Finally, dried silica aero-gel was obtained as shown in Figure 13 [17].

Scanning electron micrograph (SEM) of prepared aero-gel (Figure 14) indicates that the aero-gel was a porous material with a continuous meshwork structure. In the SEM photo, the white parts are the bulges in the surface of the aero-gel, while the black parts are pores in the aero-gel [17].

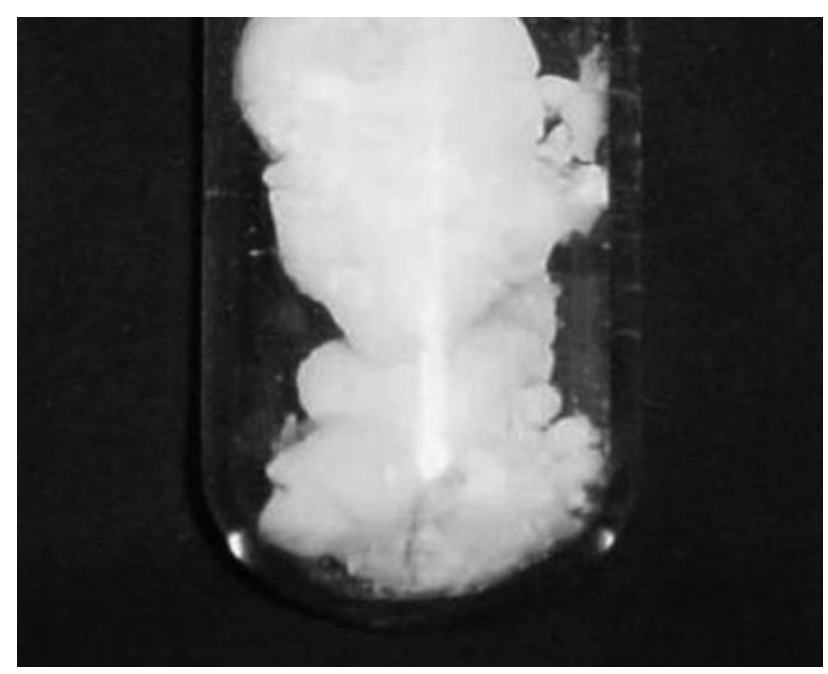

Figure 13. Photograph of prepared Silica aerogel [17]

\subsubsection{Silica aero-gel production by ambient pressure drying}

Aero-gels are generally prepared by the supercritical extraction of pore liquid from wet gels, which has certain limitations in terms of its process continuity, cost efficiency because a high temperature and pressure are needed to approach the critical point. The chemical durability of the aerogels in the atmosphere gradually decreased, if liquid carbon dioxide were used as a solvent in the LTSCD process, since the aero-gel particles are hydrophilic. To overcome these problems, Brinker and Scherer introduced [89] a commercially attractive ambient pressure drying method for the production of silica aero-gel. In this process, the surface of the wet gel is chemically modified by replacing $\mathrm{H}$ from hydroxyl groups with hydrophobic functional groups followed by ambient pressure drying. This process creates surfaces with extremely low energies, which dramatically reduces surface tension. Therefore, it is necessary to modify alco-gel surfaces with appropriate modifying agents, so that the surface of the aerogel is rendered hydrophobic. There are several hydrophobic reagents like methyltrimethoxysilane (MTMS), hexamethyldisilazane (HMDZ), dimethylchloro-silane (D M S ), dimethyldichlorosilane (DMDC), trimethylchlorosilane (TMCS), trimethylethoxysilane (TMES), and hexadecyltrimethoxysilane (HDTMS). Surface modification of the gels through the replacement of $\mathrm{H}$ from $\mathrm{Si}-\mathrm{OH}$ by non-polar alkyl or aryl groups is a crucial step in the ambient pressure drying method. That prevents

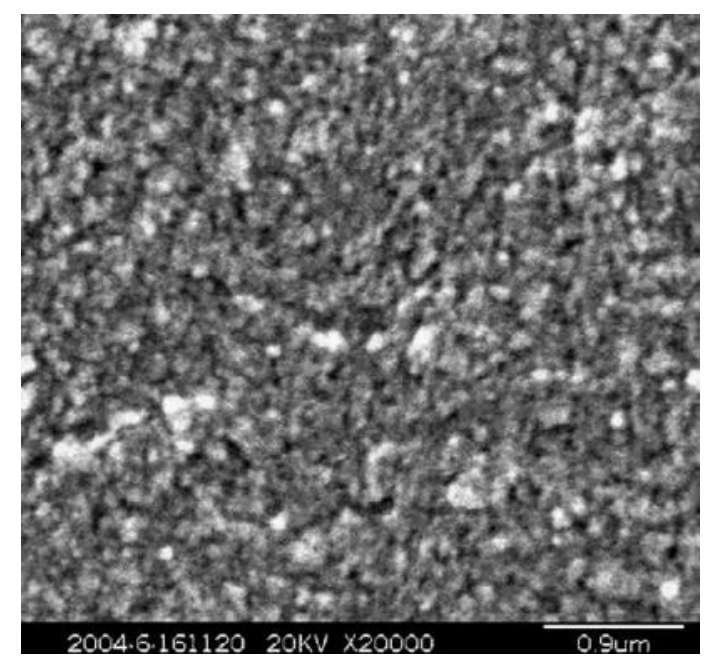

Figure 14. The SEM photo of the silica aero-gel from rice husk ash [17]. 
condensation reactions of silica clusters, and, by extension, prevents shrinkage of the gel during drying.

For highly porous aero-gel structure, elimination of capillary stress during ambient pressure drying is necessary [103]. Liquid evaporation from wet gel during drying creates a capillary tension (due to the liquid-vapour interface) and that tension is balanced by the compressive stress on the solid network, causing shrinkage of the gel [104]. Strengthening of gel network, surface modification and solvent exchange of the wet gel are necessary to suppress such type of capillary tension and shrinkage during ambient pressure drying [50, 71]. The gel should be aged in silane solution [105] to increase the strength and stiffness of it. Finally, pore liquid must be replaced by low surface tension solvent to reduce capillary stress and associated drying shrinkage.

Nayak and Bera [38] prepared silica aero-gel by ambient pressure drying using the following procedure. They extracted silica from RHA as sodium silicate solution by boiling it in sodium hydroxide solution. Silica was extracted from ash as sodium silicate by boiling it in sodium hydroxide solution. Sodium silicate was neutralized with nitric acid to form silica gel. To prepare aero-gel, first the pore water of the gel was exchanged by ethanol and then surface modification was done by aging alco-gel in tetraethylorthosilicate (TEOS)/ethanol solution. Before drying, TEOS/ethanol solvent was exchanged with nheptane. Capillary stress and shrinkages were greatly reduced due to the low surface tension of nheptane. The prepared aero-gel was a light and

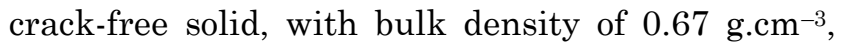
porosity of about $80 \%$, total pore volume of 3.1 $\mathrm{cm}^{3} \cdot \mathrm{g}^{-1}$ and specific surface area of about $273 \mathrm{~m}^{2} \cdot \mathrm{g}^{-}$ ${ }^{1}$ [38]. Combining the possibilities for gel formation and drying leads to at least two possible routes for ambient pressure dried silica aero-gels:

- Alkoxysilane based aero-gels [106-109]

- Waterglass based aero-gels [50, 51, 104]

Solvent exchange and surface modification are essential to preserve the porous network of the gel before ambient pressure drying (APD). However, solvent exchange is a lengthy and tedious process that involves diffusion of a solution within a gel. The large-scale production of monolithic silica aero-gels at ambient pressure would take several hours or even days because of solvent exchange. Hence, the synthesis of large-scale sodium silicatebased monolithic silica aero-gels at ambient pressure has limitations. In contrast, if silica beads are used, solvent exchange is much faster; this can considerably reduce the production time and cost
[104]. In addition, by synthesizing silica aero-gels beads, improvements in physical and textural properties such as specific surface area, pore size, and pore volume of the resulting aero-gels can be attained compared to monolithic silica aero-gels prepared at ambient pressure. Silica aero-gel beads have recently been synthesized at ambient pressure [110]. Sarawade et al. reported a method to synthesize low-density transparent mesoporous silica aero-gel beads by ambient pressure drying (APD). The beads were prepared by acid-base solgel polymerization of sodium silicate in aqueous ammonia solution via the ball dropping method (BDM). To minimize shrinkage during drying, wet silica beads were initially prepared; their surfaces were then modified using trimethylchlorosilane (TMCS) via simultaneous solvent exchange and surface modification [111].

\subsubsection{Preparation of silica hydro-gel beads using sodium silicate}

Sarawade et al. [2010] prepared silica hydro gel beads through hydrolysis and polycondensation of sodium silicate as a silica precursor (molar ratio $\mathrm{SiO}_{2}: \mathrm{Na}_{2} \mathrm{O}=3.02$ ). To prepare silica sol, aqueous sodium silicate solution was mixed with acetic acid-catalyzed water under continuous stirring. Acetic acid solution was added to the aqueous solution of sodium silicate until the solution $\mathrm{pH} \sim 4$. This procedure was executed rapidly to avoid sol gelation. Then, the sols were dropped into a container with kerosene as the upper layer and aqueous ammonia solution as the bottom layer. As the droplets come into contact with the aqueous ammonia solution ( $\mathrm{pH} 8$ ), the $\mathrm{pH}$ increased to $\sim 6$, resulting in polymerization of the silica sol (sol-togel formation) and gel bead formation. The silica beads obtained were then immersed in aqueous ammonia solution for $2 \mathrm{~h}$ at room temperature $\left(\sim 25^{\circ} \mathrm{C}\right)$, and washed with distilled water for $12 \mathrm{~h}$ to remove the sodium ions trapped inside the wet beads. After washing, the beads were removed for further simultaneous solvent exchange and surface modification [111].

\subsubsection{Simultaneous solvent exchange/ surface modification of silica wet beads}

For surface modification, wet beads were modified using ethanol/TMCS/n-hexane solution via simultaneous solvent exchange and surface modification. The simultaneous solvent exchange and surface modification process was carried out by immersing the prepared hydro gel beads in ethanol/TMCS/n-hexane solution at room temperature for $12 \mathrm{~h}$. To evaluate the effect of 

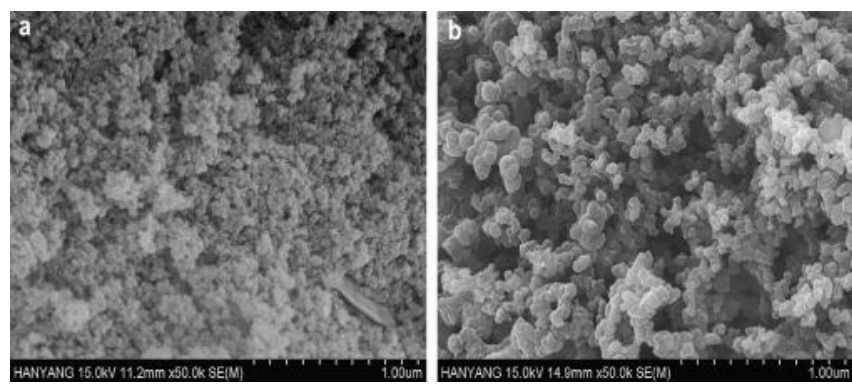

Figure 15. FE-SEM micrograph of (a) unmodified and (b) TMCS modified (10\%V of TMCS) mesoporous silica beads [112]

varying percentages of TMCS on the physicochemical properties of the silica beads, the $\% \mathrm{~V}$ of TMCS in the hexane and ethanol solution was varied from 2 to $10 \%$. After surface modification, the beads were washed with $\mathrm{n}$ hexane to remove the unreacted TMCS. The wet beads were dried at room temperature $\left(\sim 25{ }^{\circ} \mathrm{C}\right)$ for $24 \mathrm{~h}$ and then at $80^{\circ} \mathrm{C}$ for $2 \mathrm{~h}$ to reduce shrinkage during drying. To ensure complete evaporation of the pore liquid, the beads were dried at $200{ }^{\circ} \mathrm{C}$ for $1 \mathrm{~h}$. It is observed that surface area and cumulative pore volume increases on increasing the volume percent of TMCS.

The mesoporous structure of silica beads was confirmed by field emission scanning electron microscopy (FE-SEM) and transmission electron microscopy (TEM). Fig. 15 shows the pore characteristics and structure morphology of mesoporous silica beads based on FE-SEM micrographs of (a) unmodified and (b) 10\%V TMCS modified silica beads. In general, the unmodified silica beads formed dense aggregates of spheres while the modified silica beads had highly porous structures Figure 15 (b). This is because the unmodified wet gel silica beads shrank more during APD, resulting in dense aggregates of dried silica beads and the loss of mesopores [111].

\subsubsection{Silica aero-gel production by Freeze Drying}

Phase boundaries between the liquid and the gas phase during drying can also be avoided by freeze drying. In freeze drying, the pore liquid is frozen and then sublimed in vacuum [113-115]. However, the aging period must be extended to stabilize the gel network, the solvent must be replaced by one with a low expansion coefficient and a high sublimation pressure, and salts are added for attaining low freezing temperatures. Another disadvantage is that the network may be destroyed by crystallization of the solvent in the pores. Cryogels are therefore only obtained as powders [48]. Comparison between silica aero-gels prepared with different precursors and drying methods is tabulated below (Table 9).

\section{Comparison of Silica Aero-gel and Silica Xero-gel Characteristics}

Figure 16 shows comparison of the networks of wet sol-gel, xero-gel and aero-gel. Silica xero-gel is normally synthesized by sol-gel process and is formed once the gel is dried under ambient condition [117].

The morphology of silica matrices was investigated and FE-SEM micrographs are

Table 9. Comparison between silica aero-gels prepared with different precursors and drying methods

\begin{tabular}{|c|c|c|c|c|c|c|c|}
\hline $\begin{array}{l}\text { Precursor/ } \\
\text { drying } \\
\text { method }\end{array}$ & $\begin{array}{c}\text { Surface } \\
\text { Area } \\
\left(\mathrm{m}^{2} / \mathrm{g}\right)\end{array}$ & $\begin{array}{c}\text { Modifying } \\
\text { agent }\end{array}$ & $\begin{array}{c}\text { Pore } \\
\text { Volume } \\
\left(\mathrm{cm}^{3} / \mathrm{gm}\right)\end{array}$ & Color & $\begin{array}{c}\text { Pore } \\
\text { diameter } \\
(\mathrm{nm} .)\end{array}$ & $\begin{array}{c}\text { Bulk } \\
\text { density } \\
\left(\mathbf{k g} / \mathrm{m}^{3}\right)\end{array}$ & $\begin{array}{c}\text { Refer- } \\
\text { ence }\end{array}$ \\
\hline $\begin{array}{l}\mathrm{RHA} / \mathrm{Sc}-\mathrm{CO}_{2} \\
\text { drvin } \mathbf{c}\end{array}$ & 597.7 & - & 8.65 & White & 10 & 38 & [17] \\
\hline $\begin{array}{l}\text { RHA/ } \\
\text { Ambient pres- } \\
\text { sure drying }\end{array}$ & 917 & TMCS & 2.3 & $\begin{array}{l}\text { Semi- } \\
\text { transparent }\end{array}$ & 12.3 & 81 & [111] \\
\hline $\begin{array}{l}\text { RHA/ } \\
\text { Ambient pres- }\end{array}$ & 273 & TEOS & 3.1 & $\begin{array}{l}\text { Semi- } \\
\text { transparent }\end{array}$ & - & 67 & [38] \\
\hline $\begin{array}{l}\text { TEOS/ } \\
\text { Sc-ethanol } \\
\text { drying }\end{array}$ & $935-1150$ & & $8.6-10.9$ & transparent & - & $43-89$ & [116] \\
\hline
\end{tabular}




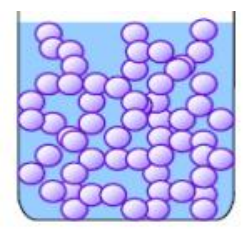

Wet Sol-gel

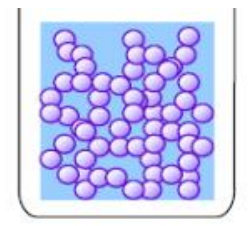

Xero-gel

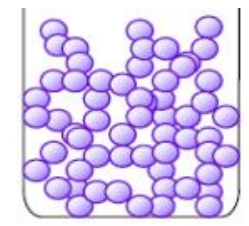

Aero-gel

Solvent

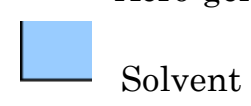

Gel Particles

Figure 16. Comparison of gel network of wet solgel, xero-gel and aero-gel [117].

illustrated in the Figures 17 and 18. The synthesized silica aero-gel exhibits porous network structure, which contains solid clusters of 10-60 $\mathrm{nm}$ and pores below $100 \mathrm{~nm}$ in between them (Figure 17). As can be seen in Figure 18, silica xero-gel has a highly dense morphology, which appears as tiny spherical nanoparticles, approximately $30-60 \mathrm{~nm}$ in diameter. The micrograph also shows the aggregates of particles in silica xero-gel. Besides that, the diffractograms reveal that the silica aero-gel and silica xero-gel are amorphous (Figure 19). Surface area of silica aero-gel is about three times higher than silica xero-gel. Silica xero-gel possesses lower surface area than silica aero-gel.

\section{Conclusion}

Rice husk, an agro waste, if burnt under controlled conditions, can be a source for many silicon-based materials. White amorphous silica of high chemical purity, X-ray amorphous, ultra fine in size and having high surface area and reactivity can be produced by acid treatment of rice husk followed by controlled burning. Applications of the rice husk silica are as filler in polymeric materials, as a possible substitute for condensed silica fume in high strength concrete, starting material for high performance silicon compounds etc. Silica aero-gels are used in variety of technological areas because of its extraordinary properties. Substantial progress has been made in the development, processing and characterization of aero-gel materials over the recent years. Special attention has been paid to the use of inexpensive precursors such as rice husk and the drying technology to make the production commercial. The unique optical, mechanical, acoustic, and thermal properties of aero-gels originate from the combination of a solid network and nanosized pores filled with air. The choice of the precursors and the optimization of sol-gel parameters

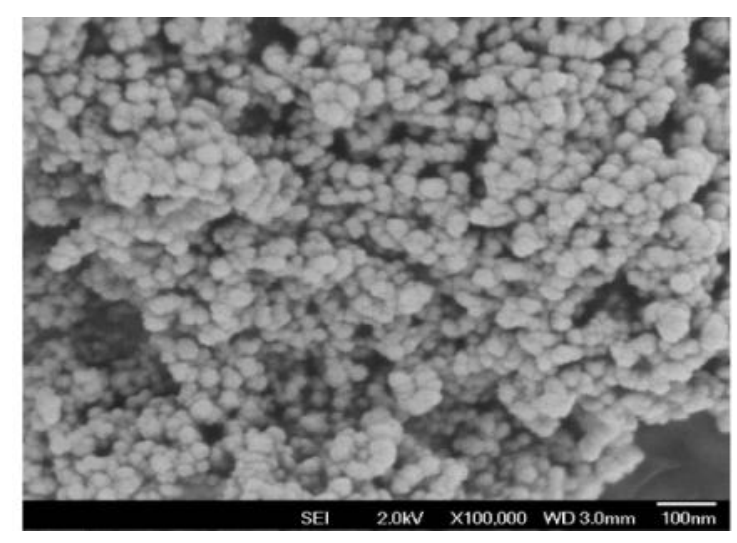

Figure 17. FE-SEM micrograph of synthesized silica aero-gel [117]

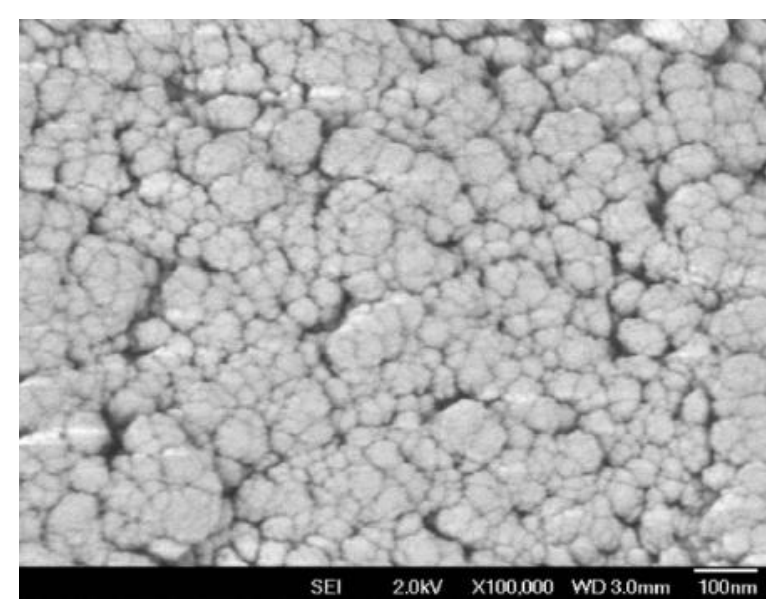

Figure 18. FE-SEM micrograph of synthesized silica xero-gel [117]

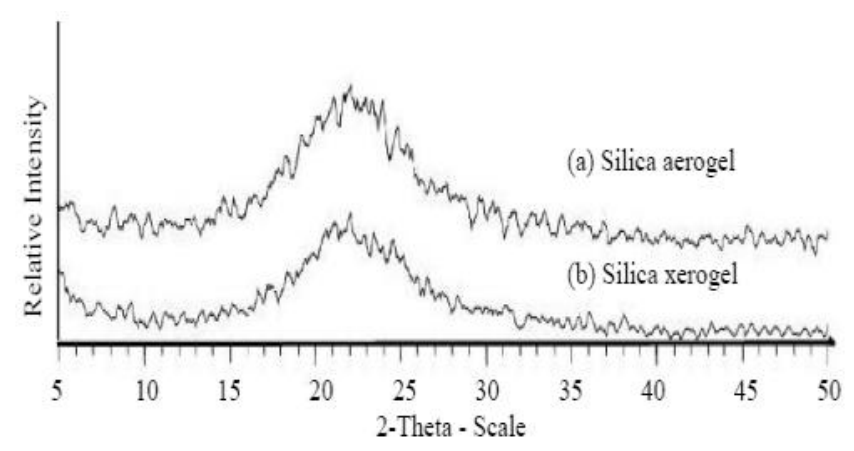

Figure 19. X-ray diffractograms of (a) silica aero-gel, and (b) silica xero-gel [117]

determine the physical properties of the final aerogel product. Drying of the alco-gels is carried out with supercritical or ambient pressure drying methods, depending upon the commercial aero-gel application. An extensive chemical modification provides a new space for studying the property of 
aero-gels. Ambient pressure drying techniques will probably make industrial preparation much cheaper and will thus make aero-gels more competitive. The most important area for the application of aero-gels is in all kinds of thermal insulation, nontoxic, nonflammable, easy to dispose of compared with most of other materials in the market. Economy of the manufacturing process improves if the fuel value of the material is also utilized. Tremendous scope exists for further research and development activities to convert all the laboratory findings into commercial production with appropriate technologies.

\section{References}

[1] Jain, A. K.; Sharma, S. K.; and Singh, D. 1996. Reaction Kinetics of Paddy Husk Thermal Decomposition: Proceedings 31th Intersociety of Energy Conversion Engineeering Conference, 4: 2274-2279. Washington D.C. ASME.

[2] Yalcin, N.; and Sevinc, V. 2001. Studies on silica obtained from rice husk. Ceram. Inter. 27: 219224 .

[3] Pijarn, N.; Jaroenworaluck, A.; Sunsaneeyametha, W.; and Stevens, R. 2010. Synthesis and characterization of nanosized-silica gels formed under controlled conditions. Powder Technol. 203 (3): 462-468.

[4] Rao, V. M. H. G. 1980. Utilization of rice husk-A preliminary analysis. J. Sci. Ind. Res. 39: 495-515.

[5] Sharma, N. K.; Williams, W. S.; and Zangvil, A. 1984. Formation and structure of silicon carbide whiskers from rice hulls. J. Am. Ceram. Soc. 67: 715-720.

[6] Patel, M.; Karera A.; and Prasanna, P. 1987. Effect of thermal and chemical treatments on carbon and silica contents in rice husk. J. Mater. Sci. 22: 2457-2464.

[7] Patel, M.; Karera, A.; 1991. SiC whisker from rice husk: Microscopic study. Powder Metall. Int. 23 (1): 30-32.

[8] Ding, M. 1992. Rice husk silicon and its applications. Inorg. Chem. Ind. 24 (6): 36-42.

[9] Krishnarao, R. V.; and Godkhindi, M. M.; 1992. Distribution of silica in rice husks and its effect on the formation of silicon carbide. Ceram. Int., 18: $243-249$.

[10] Chandrasekhar, S.; Satyanarayana, K. G.; Pramada, P. N.; and Raghavan P. 2003. Review Processing, properties and applications of reactive silica from rice husk- an overview. J. Mat. Sci. 38: $3159-3168$.

[11] Rao, R. V. Krishna; Godkhindi, Andm. M.; 1992. Effect of $\mathrm{Si}$ additions on the formation of $\mathrm{SiC}$ whiskers from rice husks. Ceram. Int. 18:185.

[12] Ismail, Muhammad Shoaib.; and Waliuddin, A. M. 1996. Effect of rice husk ash on high strength Concrete. Const. and Build. Mat. 10: 521-526.

[13] Proctor, A.; Clark, P.K.; and Parker, C.A. 1995. Rice hull ash adsorbent performance under commercial soy oil bleaching conditions. J. Am. Oil Chem. Soc. 72: 459-462.

[14] Proctor, A.; and Palaniappan, S. 1990. Adsorption of soy oil free fatty acids by rice hull ash. J. Am. Oil Chem. Soc. 67: 15-17.

[15] Sun, L.; and Gong, K.; 2001. Review, silicon-based materials from rice husks and their applications. Ind. Eng. Chem. Res. 40: 5861-5877.

[16] Krishna Rao, R. V.; Subrahmanyam, J.; and Kumar T. J. 2001. Studies on the formation of black particles in rice husk silica ash. J. Eur. Ceram. Soc. 21(1): 99-104.

[17] Tang, Qi.; and Wang Tao. 2005. Preparation of silica aero-gel from rice hull ash by supercritical carbon dioxide drying. J. Supercritical Fluids 35: 91-94.

[18] Bhattacharya S. C.; and Wu, W. 1989. Fluidized bed combustion of rice husk for disposal and energy recovery. Energy from Biomass \& wastes 12: $591-601$.

[19] Boaterg, S. D. A. 1990. Incineration of rice hull for use as a cementitious material. Cem. Concr. Res. 20(5): 795-802.

[20] Huang, S.; Jing, S.; Wang, J.; Wang, Z.; and Jin, Y. 2001. Silica white obtained from rice husk in fluidized bed. Powder Tech. 117: 232-238.

[21] Mochidzuki, K.; Sakoda, A.; Suzuki, M.; Izumi, J.; and Tomonaga, N. 2001. Structural behavior of rice husk silica in pressurized hot-water treatment process. Indus. Eng. Chem. Res. 40: $5705-5709$.

[22] Liou, T.-H. 2004. Evolution of chemistry and morphology during the carbonization and combustion of rice husk. Carbon 42: 785-794.

[23] Liou, T.-H. 2004. Preparation and characterization of nano-structured silica from rice husk. Mat. Sci. Eng. 364: 313-323.

[24] Kalapathy, U.; Proctor, A.; and Schultz, J. 2000a. A simple method for production of pure silica from rice hull ash. Biores. Tech. 73: 257-262.

[25] Shelke, V. R.; Bhagade, S. S.; and Mandavgane, S. A. 2010. Mesoporous Silica from Rice Husk Ash. Bull. Chem. React. Eng. Catal. 5(2): 63-67

[26] Sidheswaran P.; and Bhat A. N. 1996. Recovery of amorphous silica in pure form from rice husk. Trans. Ind. Ceram. Soc. 55(4): 93-96.

[27] Hamad, M. A.; and Khattab, I. A. 1981. Effect of 
the combustion process on the structure of rice hull silica, Thermochim. Acta 48: 343-349.

[28] Real, C.; Alcala, M. D.; and Criado, J. M. 1996. Preparation of silica from rice husks. J. Am. Ceram. Soc. 79(8): 2012-2016.

[29] Hanafi, S.; Abo-El-Enein, S. A.; Ibrahim, D. M.; and El-Hemaly, S. A. 1980. Thermochim. Acta 37: 137-143.

[30] Chakraverty, A.; Mishra, P.; and Banerjee, H. D. 1988. Investigation of combustion of raw and acidleached rice husk for production of pure amorphous white silica. J. Mater. Sci. 23(1): 2124.

[31] Liou, T.-H.; Yang, C.-C. 2011. Synthesis and surface characteristics of nanosilica produced from alkali-extracted rice husk ash. Mat. Sci. Eng. B 176: 521-529.

[32] Kamath, S. R.; Proctor, A. 2004. Silica gel from rice husk ash: preparation and characterization. Cer. Chem.75:484-487.

[33] Polska, K.; Radzki, S. 2008. Spectral and AFM characterization of trimethylammoniophenylporphyrin and concanavalin A associate in solution and monolithic $\mathrm{SiO}_{2}$ gels obtained by the sol-gel method. Opt. Mat. 30: 1644-1654.

[34] Estella, J.; Echeverría, J. C.; Laguna, M.; Garrido, J. J. 2007. Effects of aging and drying conditions on the structural and textural properties of silica gels. Micro. Meso. Mat. 102: 274- 282.

[35] Handy, B.; Walther, K. L.; Wokaun, A.; and Baiker, A. 1991. Influence of preparation parameters on pore structure of silica gels prepared from tetraethoxy orthosilicate. Stud. Sur. Sci. Cat. 63: 239-246.

[36] Monde, T.; Fukube, H.; Nemoto, F.; Yoko, T.; and Konakahara, T.1999. Preparation and surface properties of silica gel coating films containing branched-polyfluoroalkylsilane. J. NonCrystalline Solids 246: 54-64.

[37] Kamath Savita R.; and Proctor Andrew ; 1998. Silica Gel from Rice Hull Ash: Preparation and Characterization. Cereal Chem. 75(4): 484-487.

[38] Nayak, J. P.; and Bera J. 2009. Preparation of Silica Aero-gel by ambient pressure drying process using rice husk ash as raw material. Trans. Ind. Ceram. Soc. 68(2): 1-4.

[39] Einarsruda, Mari-Ann; Haereida, Siv; and Wittwerb Volker; 1993. Some thermal and optical properties of a new transparent silica xero-gel material with low density, Solar Ener. Mat. Solar Cel. 31(3): 341-347.

[40] Affandi, Samsudin; Setyawan, Heru; Winardi, Sugeng ; Purwanto, Agus ; and Balgis, Ratna; 2009. A facile method for production of highpurity silica xero-gels from bagasse ash. Advan.
Powd. Technol. 20: 468-472.

[41] Hong, Jung-Kyun; Yang, Hee-Sun; Moon-Ho Jo, Park Hyung-Ho; and Choi Se-Young; 1997. Preparation and characterization of porous silica xero-gel film for low dielectric application. Thin Solid Films 308: 495-500.

[42] Chakraverty, A.; Kaleemullah, S. 1991. Conversion of rice husk into amorphous silica and combustible gas. Energy Convers. Manage. 32: 565-570.

[43] Luan, T. C.; Chou, T. C. 1990. Recovery of silica from the gasification of rice husk/coal in the presence of a pilot flame in a modified fluidized bed. Ind. Eng. Chem. Res. 29: 1922-1927.

[44] Iler, R. K. 1979. Silica gels and powders. The Chem. of Silica R. K. Iler. (Ed.) 462-599.

[45] Kalapathy U.; Proctor A.; Shultz J. 2002. An improved method for production of silica from rice hull ash. Biores. Tech. 85: 285-289.

[46] Hrubesh, L. W. 1990. Aero-gels: the world's lightest Solids. Chem. Indus. 24: 824-827.

[47] Fricke, J.; and Emmerling, A. 1992. Aero-gels, preparation, properties, applications, in Structure and Bonding. Springer Ser. Structure Bonding 77: 37-87.

[48] Gurav, J. L.; Jung, I.-K.; Park, H.-H.; Kang E. S. and Nadargi, D. Y. 2010. Silica Aero- gel: Synthesis and Application. J. Nano Mat. 1-11

[49] Dorcheh A. Soleimani.; Abbasi M. H. 2008. Silica Aero-gel; Synthesis, Properties and Characterization. J. Mat. Proc. Tech. 199: 10-26.

[50] Schwertfeger, F.; Frank D.; and Schmidt, M. 1998. Aero-gel-High Tenuous Solids with Fascinating Properties. J. Non-Cryst. Solids 225: 24-29.

[51] Robert R. Keller, Sr. 2009. Aero-gel and method of manufacturing same. US Patent 7618608.

[52] Lee, C. J.; Kim, G. S.; and Hyun, S.H. 2002. Synthesis of silica aero-gels from waterglass via new modified ambient drying. J. Mater. Sci. 37: 2237-2241.

[53] Rao, A. P.; Pajonk, G.M.; and Rao, A.V. 2005. Effect of preparation conditions on the physical and hydrophobic properties of two step processed ambient pressure dried silica aerogels. J. Mater. Sci. 40: 3481-3489.

[54] Husing, N.; and Schubert, U. 1998. Aero-gels-Airy materials: Chemistry, structure, and properties. Angew. Chem. Int. Ed. 37: 22-45.

[55] Rousset, J. L.; Boukenter, A.; Champagnon B. 1990. Granular structure and fractal domains of silica aero-gels J. Phy: Conden. Mat., 2(42): 84458455 . 
[56] Liu, C.; Komarneni, S.; Smith, D. M.; Beck, J.S. (Eds.) 1995. Advances in Porous Materials. Mater. Res. Soc. Symp. Proc. 371: 217-222.

[57] Komarneni, S.; Roy, R.; Selvaraj, U.; Malla, P. B.; and Breval, E. 1993. Biocompatibility of polymeric delivery systems for macromolecules. J. Mater. Res. 8: 3163- 3167.

[58] Attia, Y.A.; Ahmed, M.S.; Zhu, M.; Attia, Y.A. (Ed.). 1994. Sol-Gel Processing and Applications. J. Sol-Gel Sci. Technol. 311-315.

[59] Shi, F.; Wang, L.; and Liu, J. 2006. Synthesis and characterization of silica aero-gels by a novel fast ambient pressure drying process. Mater. Lett. 60: 3718-3722.

[60] Wagh, P.B.; Begag, R.; Pajonk, G.M.; Rao, A.V.; Haranath, D. 1999. Comparison of some physical properties of silica aero-gel monoliths synthesized by different precursors. Mater. Chem. Phys. 57: $214-218$.

[61] Kim, G. S.; Hyun, S. H. 2004. Synthesis and characterization of silica aero-gel films for intermetal dielectrics via ambient drying. Thin Solid Films 460: 190-200.

[62] Drake, J. M.; Yacullo, L. N.; Levitz, P.; and Klafter, J. 1994. Nitrogen Adsorption on Porous Silica: Model-Dependent Analysis. J. Phys. Chem. 98: 380-382.

[63] Reichenauer, G.; and Scherer, G.W. 2001. Nitrogen sorption in aero-gels. Adsorption isotherms -hysteresis. J. Non-Cryst. Solids 285: 167-174.

[64] Moner-Girona, M.; Roig, A.; and Molins, E. 2003. Sol gel route to direct formation of silica aero-gel microparticles using supercritical solvents. J. SolGel Sci Technol. 26: 645-649.

[65] Woignier, T.; and Phalippou, J. 1987. Skeletal density of silica aero-gels. J. Non-Cryst. Solids 93: 17-21.

[66] Kamiuto, K.; Saitoh, S.; and Tokita, Y. 1993. Scattering phase function of a silica aerogel at $450 \mathrm{~nm}$ wavelength J. Quant. Spectrosc. Radiant. Trans. 50: 293-327.

[67] Beck, Caps, R.; Frick, J. 1989. Scattering of Visible Light from Silica Aero-gels. J. Phys. D 22: 730-734.

[68] Jensen, K. I.; Schultz, J. M.; and Kristiansen, F. H. 2004. Development of windows based on highly insulating aero-gel glazing. J. Non-Cryst. Solids 350: 351-357.

[69] Schultz, J. M.; Jensen, K.I.; and Kristiansen, F. H. 2005. Super insulating aerogel glazing:Sol. Sol. Ener. Mat. Sol. cells. 89: 275-285.

[70] Buzykaev, A. R.; Danilyuk, A. F.; Ganzhur, S. F.; Kravchenko, E. A.; and Onuchin, A. P. 1999. Measurements of optical parameters of aero-gel.

\section{Nucl. $\quad$ Instr. Meth. Phys. Res. A 433: 396-400.}

[71] Rao, A. Venkateswara; Nilsen E.; and Einarsrud, M. A. 2001. Effect of Precursors, Methyalation Agents and Solvents on the Physicochemical Properties of Silica Aero-gels Prepared by Atmospheric Pressure Drying Method. J. NonCryst. Solids, 296: 165-171.

[72] Kistler, S. S.; 1932. Coherent expanded aero-gels. J. Phys. Chem. 36: 52-64.

[73] Lee, K.-H.; Kim, S.-Y.; and Yoo, K. P. 1995. Lowdensity, hydrophobic aero-gels. J. Non-Cryst. Solids 186: 18-22.

[74] El Rassy, H.; Pierre, A.C.; 2005. NMR and IRspectroscopy of silica aerogels with different hydrophobic characteristics. J. Non-Cryst. Solids 351: 1603-1610.

[75] Deshpande, R.; Smith, D.; and Brinker, C.J. 1996. Preparation of High Porosity Xero-gels by Chemical Surface Modification US Patent 5, 565,142 .

[76] Hrubesh, L. W. 1998. Aero-gel applications. J. Non-Cryst. Solids 225: 335-342.

[77] Schmidt, M.; Schwertfeger, F. 1998. Applications for silica aero-gel products. J. Non-Crystal. Solids 225: 364-368.

[78] Ulrich, D.R. 1990. Prospects for sol-gel processes. J. Non-Cryst. Solids 121: 465-479.

[79] Fricke, J.; Tillotson, T. 1997. Aero-gels: production, characterization, and applications. Thin Solid Film 297: 212-223.

[80] Pierre, A.C.; Pajonk, G. M. 2002. Chemistry of aero-gels and their applications. Chem. Rev. 102:4243-4265.

[81] Adachi, I.; Sumiyoshi, T.; Hayashi, K.; Iida, N.; Enomoto, R.; Tsukada, K.; Suda, R.; Matsumoto, S.; Natori, K.; Yokoyama, M.; and Yokogawa, H. 1995. Study of threshold Cherenkov counter based on silica aerogels with low refractive indices. Nucl. Instr. Meth. Phys. Res. A 355: 390398.

[82] Asner, D.; Butler, F.; Dominick, J.; Fadeyev, V.; Masek, G.; Nemati, B.; Skubic, P.; and Strynowski, R. 1996. Experimental study of aerogel Cherenkov detectors for particle identification. Nucl. Instr. Meth. Phys. Res. A 374: 286-292.

[83] Sumiyoshi, T.; Adachi, I.; Enomotoi, R.; Iijima, T.; Suda, R.; Yokoyama, M.; and Yokogawa, H. 1998. Silica aero-gels in high energy physics. $J$. Non-Cryst. Solids 225: 369-374.

[84] Ishino, M.; Chiba, J.; En'yo, H.; Funahashi, H.; Ichikawa, A.; Ieiri, M.; Kanda, H.; Masaike, A.; Mihara, S.; Miyashita, T.; Murakami, T.; Nakamura, A.; Naruki, M.; Muto, R.; Ozawa, K.; Sato, H.D.; Sekimoto, M.; Tabaru, T.; Tanaka, K. 
H.; Yoshimura, Y.; Yokkaichi, S.; Yokoyama, M.; and Yokgawa, H. 2001. Mass production of hydrophobic silica aero-gel and readout optics of Cherenkov light. Nucl. Instr. Meth. Phys. Res. A 457: 581-587.

[85] DeLeo, R.; Lagamba, L.; Manzari, V.; Nappi, E.; Scognetti, T.; Alemi, M.; Becker, H.; Forty, R.; Adachi, I.; Suda, R.; Sumiyoshi, T.; Leone, A.; Perrino, R.; Matteuzzi, C.; Seguinot, J.; Ypsilantis, T.; Cisbani, E.; Frullani, S.; Garibaldi, F.; Iodice, M.; and Uriuoli, G.M. 1997. Electronic detection of focused Cherenkov rings from aerogel. Nucl. Instr. Meth. Phys. Res A 401: 187-205.

[86] Anappara, A. A.; Rajeshkumar, S.; Mukundan, P.; Warrier, P. R. S.; Ghosh, S.; Warrier, K. G. K. 2004. Impedence spectroscopic studies of sol-gel derived subcritically dried silica aero-gels. Acta Mater. 52: 369-375.

[87] Rao, A. V.; Kulkarni, M. M.; Amalnerkar, D. P.; and Seth, T. 2003. Silica aero-gels based on methyltrimethoxysilane precursor. J. Non-cryst. Solids 330: 187-195.

[88] Nyquist, R. A.; Putzig, C. L.; Leugers, M. A.; Kagel, R. O.; and Nyquist, R. A. 1997. The handbook of infrared and Raman spectra of inorganic compounds and organic salts. San Diego: Academic Press. 18th Edn.

[89] Brinker, C. J.; and Sherer, G.W. 1990. The Physics and Chemistry of Sol-Gel Processing. Academic Press.

[90] Nicolaon, G. A.; and Teichner, S.J. 1968. Preparation of silica aero-gels from methyl orthosilicate in alcoholic medium, and their properties. Bull. Soc. Chim., 5: 1906 -1911.

[91] Poco, J. F.; Coronado, P. R.; Pekala, R. W.; and Hrubesh, L.W. 1996. A Rapid Supercritical Extraction Process for the Production of Silica Aero-gels. Mater. Res. Soc. Symp. 431: 297-302.

[92] Gross, J.; Coronado, P.; and Hrubesh, L. 1998. Elastic properties of silica aero-gels from a new rapid supercritical extraction process. J. NonCryst. Solids 225: 282-286.

[93] Scherer, G.W.; Gross, J.; Hrubesh, L. W.; and Coronado, P. R. 2002. Mechanical Properties of Silica Alco-gels and Aero-gels. J. Non-Cryst. Solids 311: 259-272.

[94] Gauthier, B. M.; Bakrania, S. D.; Anderson, A. M.; and Carroll, M. K. 2004. Extraction Technique for Aero-gel Fabrication. J. Non-Cryst. Solids 350: 238-243.

[95] Kirkbir, F.; Murata, H.; Meyers, D.; and Ray Chaudhuri, S. 1998. Proceedings of the Fifth International Symposium on Aero-gels. J. NonCryst. Solids 225: 14-18.

[96] Tewari, P. H.; Hunt, A. J.; and Lofftus, K.D. 1985. Ambient-Temperature Supercritical Drying of
Transparent Silica Aero-gels. Mater. Lett. 3: 363367.

[97] Novak, Z., Knez, Z., and Hadolin, M. 1999. Second European Congress of Chemical Engineering. Montpellier.

[98] Wawrzyniak, P.; Rogacki, G.; Pruba, J.; and Bartczak, Z. 2001. Effective diffusion coefficient in the low temperature process of silica aerogel production. J. Non-Cryst. Solids 285: 50-56.

[99] Ehrburger-Dolle, F.; Dallamano, J.; Elaloui, E.; Pajonk, G. 1995. Relations between the texture of silica aero- gels and their preparation. $J$. Non-Cryst. Solids 186: 9- 17.

[100] Yoda, S.; Ohshima, S. 1999. Supercritical drying media modification for silica aero-gel preparation. J. Non-Cryst. Solids 248: 224-234.

[101] Dieudonne, P.; Hafidi Alaoui, A.; Delord, P.; and Phalippou, J. 2000. Transformation of nanostructure of silica gels during drying. J. NonCryst. Solids 262: 155-161.

[102] Tajiri, K.; and Igarashi, K. 1998. The effect of the preparation conditions on the optical properties of transparent silica aero-gels. Solar Ener. Mater. Solar Cel. 54: 189-195.

[103] Land, V. D.; Harris, T. M.; and Teeters, D. C. 2001. Processing of low-density silica gel by critical point drying or ambient pressure drying. J. Non-Cryst. Solids. 283: 11-17.

[104] Rao, A. Venkateswara.; Rao, A. Parvathy.; and Kulkarni, M. M. 2004. Influence of gel aging and $\mathrm{Na}_{2} \mathrm{SiO}_{3} / \mathrm{H}_{2} \mathrm{O}$ molar ratio on monolithicity and physical properties of water-glass-based aero-gel dried at atmospheric pressure. J. Non-Cryst. Solids, 350: 224-229.

[105] Haereid, S.; Nilsen, E.; and Einarsrud, M. A. 1996. Properties of silica gels aged in TEOS. J. Non-Cryst. Solids, 204: 228-234.

[106] Rao, A. P.; Pajonk, G. M.; and Rao, A. V. 2005a. Hydrophobic and physical properties of the ambient pressure dried silica aero-gels with sodium silicate precursor using various surface modification agents. J. Mater. Sci. 40: 3481-3489.

[107] Davis, P. J.; Brinker, C. J.; and Smith, D. M. 1992a. Pore structure evolution in silica gel during aging/drying I. Temporal and thermal aging. J. Non-Cryst. Solids 142: 189-196.

[108] Davis, P.J.; Brinker, C.J.; Smith, D. M.; and Assink, R. A. 1992b. Pore structure evolution in silica gel during aging/drying II. Effect of pore fluids. J. Non-Cryst. Solids 142: 197-207.

[109] Deshpande, R.; Hua, D. W.; Smith, D. M.; and Brinker, C. J. 1992. Pore structure evolution in silica gel during aging/drying. III. Effects of surface tension. J. Non-Cryst. Solids 144: 32-34. 
[110] Bhagat, S. D.; Kim, Y. H.; Ahn, Y.S.; and Yeo, J. G. 2007. Textural Properties of Ambient Pressure Dried Water Glass Based Silica Aero-gel Beads: One Day Synthesis. Micro. Meso. Mater. 96: 237244 .

[111] Sarawade, Pradip B.; Kim, Jong-Kil.; Hilonga, Askwar.; Kim, Hee Taik. 2010. Production of lowdensity sodium silicate-based hydrophobic silica aero-gel beads by a novel fast gelation process and ambient pressure drying process. Solid State Sci. 12: $911-918$.

[112] Gurav, J. L.; Rao, A.V.; Rao, A. P.; Nadargi, D. Y.; and Bhagat, S.D. 2009. Physical Properties of Sodium Silicate Based Silica Aerogels Prepared by Single Step Sol-Gel Process Dried at Ambient Pressure. J. Alloys Compound. 476: 397-402.

[113] Klvana, D.; Chaouki, J.; Repellin-Lacroix, M.; and Pajonk, G. M. 1989. A new method of preparation of aero-gel like materials using a freeze-drying process. Le Journal de Physique Colloques 50: (C4-29-C4-32)

[114] Mathieu, B.; Blacher, S.; Pirard, R.; Pirard, J. P.;
Sahouli, B.; and Brouers, F.1997. Freeze-dried resorcinol-formaldehyde gels. J. Non-Cryst. Solids, 212: 250-261.

[115] Pajonk, G. M. 1989. Drying methods preserving the textural properties of gels. Le Journal de Physique Colloques, 50: (C4-13-C4-22).

[116] Stolarski, M.; Walendziewski, J.; Steininger, M.; Pniak, B. 1999. Synthesis and characteristic of silica aero-gels, Appl. Catal. A: Gen. 177: 139-148.

[117] Yunos Nurul Hidayah Mohd; 2010. Loading capacity and release property of piperine loaded silica aero-gel and silica xero-gel. MSc Thesis. (Chemistry) Faculty of Science Universiti Teknologi Malaysia. 